\title{
Optimum Time-Censored Constant-Stress PALTSP for the Burr Type XII Distribution Using Tampered Failure Rate Model
}

\author{
P. W. Srivastava and D. Sharma \\ Department of Operational Research, University of Delhi, Delhi 110007, India \\ Correspondence should be addressed to P. W. Srivastava; preetisrivastava.saxena@gmail.com
}

Received 31 October 2013; Revised 11 April 2014; Accepted 11 April 2014; Published 18 June 2014

Academic Editor: Shey-Huei Sheu

Copyright (C) 2014 P. W. Srivastava and D. Sharma. This is an open access article distributed under the Creative Commons Attribution License, which permits unrestricted use, distribution, and reproduction in any medium, provided the original work is properly cited.

\begin{abstract}
This paper presents optimum design of time-censored constant-stress partially accelerated life test sampling plan (PALTSP) in which each item runs either at use or at accelerated conditions and product life follows Burr type XII. The optimal plan consists in finding out sample proportions allocated to both use and accelerated conditions by minimizing the asymptotic variance of test statistic for deciding on acceptance/rejection of the lot such that producer's and consumer's interests are safeguarded. The method developed has been illustrated using an example. Sensitivity analysis has also been carried out.
\end{abstract}

\section{Introduction}

Quality control methods are commonly used to determine the acceptability of a product with regard to its usefulness at the time it is put into the service. Reliability is related to the concept of quality of performance. Achieving desirable standards of reliability requires careful analysis in the product design phase. Analysis of data, obtained on a timely basis during product performance, keeps the design and production parameters updated and ensures that the product continues to perform in an acceptable manner. Reliability is built in through quality of design.

Acceptance sampling plans (ASPs) are commonly used to determine the acceptability of a product. If the sample data are related to the reliability of items (e.g., lifetimes or number of failures), then the corresponding ASP is called life test sampling plan or reliability acceptance sampling plan.

Many modern high reliability products are designed to operate without failure for a very long time. Life testing for these products under normal operating conditions is time consuming as it takes a lot of time to obtain reasonable failure information. Introducing ALT in life test sampling plan can be a good way to overcome such a difficulty. This has necessitated the formulation of ALTSPs. ALTSPs differ in the assumed life distribution, censoring schemes, failure monitoring method, test condition, and so forth.
Life test under accelerated environmental conditions may be fully accelerated or partially accelerated. In fully accelerated life testing all the test units are run at accelerated condition, while in partially accelerated life testing they are run at both normal and accelerated conditions. Commonly used stress loadings are constant-stress and step-stress (see Nelson [1]). Under constant-stress PALT each item is tested either at normal operating condition or at accelerated condition only. However, in step-stress PALT, a test item is first run at normal operating condition and, if it does not fail then, it is run at accelerated condition until failure occurs or the observation is censored. Accelerated test condition includes stresses in the form of temperature, voltage, pressure, vibration, cycling rate, humidity, and so forth.

Several authors have studied the problem of designing PALT under constant-stress loading. Yang [2] has indicated that constant-stress accelerated life tests are widely used to save time and money. DeGroot and Goel [3] have considered a PALT and estimated the parameters of the exponential distribution and the acceleration factor using the Bayesian approach. Bai et al. [4] have used the maximum likelihood method to estimate the scale parameter and the acceleration factor for the log normally distributed lifetime, using type I censoring data. Ismail [5] has used maximum likelihood and Bayesian methods for estimating the acceleration factor 
and the parameters of Pareto distribution of the second kind. Also, Bhattacharyya and Soejoeti [6] have estimated the parameters of the Weibull distribution and acceleration factor using maximum likelihood method. Bai and Chung [7] have considered optimal designs for both constant and step PALTs under type I censoring. Abdel-Hamid [8] has used the constant-stress PALT and estimated the parameters of the Burr type XII distribution and the acceleration factor under progressive type II censoring

However, no work seems to exist in the literature with PALT incorporated in acceptance sampling plan to facilitate formulation of decision rules for accepting or rejecting a lot of high reliability items satisfying producer's and consumer's requirements. In this paper optimum timecensored constant-stress PALT sampling plans have been designed using hazard acceleration and the Burr type XII life distribution. Single sample acceptance sampling plans by variables are used, and acceptance/rejection decision of a lot is based on Schneider's [9] approach to $k$-method wherein sample mean and standard deviation are replaced by MLEs of location parameter and scale parameter of log life distribution, respectively. The asymptotic variance of the test statistic so obtained is used for deciding on lot disposition. The optimal plan consists in finding out sample proportions allocated to both use and accelerated conditions for the constant PALT by minimizing the asymptotic variance of test statistic for deciding on acceptance/rejection of the lot such that producer's and consumer's interests are safeguarded.

\section{Model Assumptions and Test Procedure}

\subsection{Assumptions}

(a) The lifetime of an item tested either at normal operating condition or at accelerated conditions follows Burr type XII distribution.

(b) The lifetimes of test units are independent and identically distributed random variables.

(c) Tampered failure rate (TFR) model is assumed (Bhattacharyya and Soejoeti [6]).

(d) The log-lifetimes $T_{i}, i=1,2, \ldots, n \phi_{1}$, of items allocated to normal operating condition and the $\log$-lifetimes $T_{1 j}, j=1,2, \ldots, n \phi_{2}$, and $T_{2 j}, j=$ $1,2, \ldots, n \phi_{3}$, of items allocated to accelerated conditions are mutually independent.

\subsection{Test Procedure}

(a) The test is conducted with three test chambers, namely, one in which items are tested at normal operating condition, the second in which acceleration factor, $A_{1}$, is applied to the test items, and the third in which acceleration factor, $A_{2}$, is applied to the test items. Out of total " $n$ " items, " $n \phi_{1}$ " items randomly chosen are allocated to normal operating condition, " $n \phi_{2}$ " items are allocated to first accelerated condition, $A_{1}$, and the remaining " $n \phi_{3}$ " items are allocated to second accelerated condition, $A_{2}, \phi_{1}+\phi_{2}+\phi_{3}=1$. (b) The test is continued until

(i) failure of all test items, or

(ii) a prescribed censoring time $\eta$

whichever occurs earlier, and the test condition should remain the same.

\section{Burr Type XII Life Distribution}

The Burr type XII distribution has a nonmonotone hazard function, which can accommodate many shapes of hazard function.

The pdf and cdf, respectively, of Burr type XII distribution are

$$
\begin{gathered}
g(y ; c, k, \alpha)=\left(\frac{k c}{\alpha}\right) \cdot\left(\frac{y}{\alpha}\right)^{c-1} \cdot\left(1+\left(\frac{y}{\alpha}\right)^{c}\right)^{-(k+1)} \\
y \geq 0, c>0, k>0, \alpha>0 \\
G(y ; c, k, \alpha)=1-\left(1+\left(\frac{y}{\alpha}\right)^{c}\right)^{-k} \\
y \geq 0, c>0, k>0, \alpha>0
\end{gathered}
$$

where $c$ and $k$ are shape parameters and $\alpha$ is a scale parameter. The Burr $(c, k, \alpha)$ is unimodal, and its mode is $Y_{\text {mode }}=$ $\alpha((c-1) /(c k+1))^{1 / c}$ if $c>1$ and the pdf is $L$-shaped if $c \leq 1$. by

The reliability function and hazard rate function are given

$$
\begin{gathered}
\bar{G}(y)=\left(1+\left(\frac{y}{\alpha}\right)^{c}\right)^{-k}, \quad y \geq 0, c>0, k>0, \alpha>0, \\
h(y)=\frac{g(y)}{R(y)}=\left(\frac{k c}{\alpha}\right) \cdot\left(\frac{y}{\alpha}\right)^{c-1} \cdot\left(1+\left(\frac{y}{\alpha}\right)^{c}\right)^{-1}, \\
y \geq 0, c>0, k>0, \alpha>0 .
\end{gathered}
$$

The exponential distribution follows from Burr type XII distribution as $k \rightarrow \infty$, such that $\alpha=k^{1 / 2}$ and $c=1$. The Weibull life distribution also follows from Burr type XII distribution as $k \rightarrow \infty$, such that $\alpha=k^{1 / 2}$. For $k=1$, the Burr type XII distribution reduces to log-logistic distribution.

\section{Tampered Failure Rate Model}

Bhattacharyya and Soejoeti [6] have proposed the TFR model for step-stress PALT. Their model assumes that a change in the stress has a multiplicative effect on the failure rate function over the remaining life. In this paper TFR model has been used in constant-stress PALT. Consider a constantstress PALT wherein a test unit is tested either under use condition or under accelerated conditions till the censoring time. Let there be $(m+1)$ test chambers in all including one in which the items are tested under normal operating condition. The TFR model assumes that the effect of changing acceleration factor $A_{i-1}$ in $(i-1)$ th test chamber to $A_{i}$ in $i$ th test chamber is to multiply the failure rate function $h_{i-1}(y)$ by $A_{i}, i=1,2, \ldots, m$. Thus, the effect of changing stress 
through acceleration factor in different test chambers has multiplicative effect on initial failure rate function. Hence, the tampered failure rate model is given by

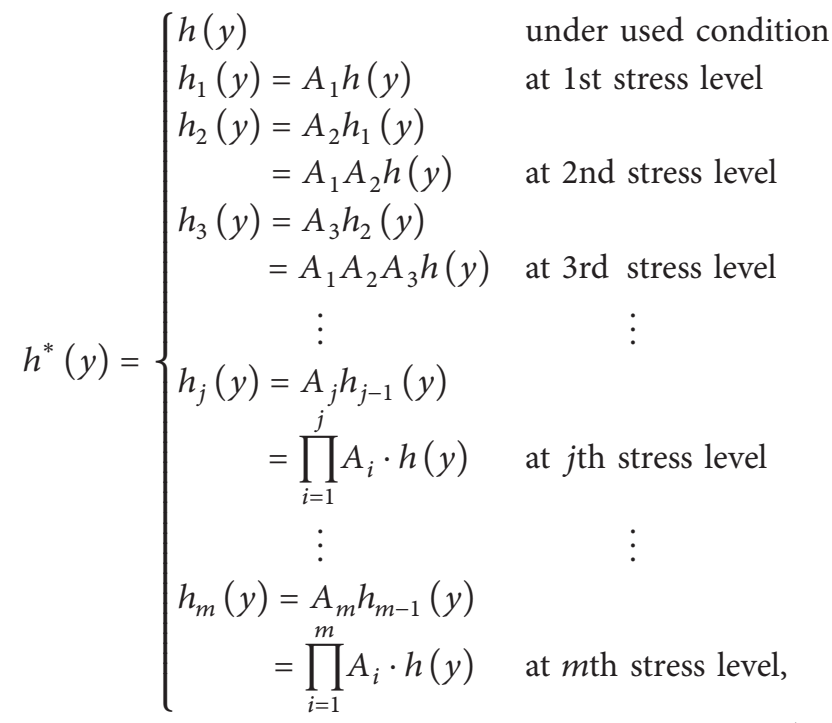

where $A_{i}>1 \forall i=1,2, \ldots, m$.

Unlike fully accelerated life testing wherein a regression structure on the stress variable (e.g., temperature and voltage) is specified, the acceleration factor $A_{i}, i=1,2, \ldots, m$, is assumed to be a parameter of the model in PALT.

Let $A_{i}^{*}=\prod_{k=1}^{i} A_{i}$; then (4a) can be rewritten as

$$
h^{*}(y)=\left\{\begin{array}{cl}
h(y) & \text { under normal condition } \\
h_{1}(y)=A_{1}^{*} h(y) & \text { at 1st stress level } \\
h_{2}(y)=A_{2}^{*} h(y) & \text { at 2nd stress level } \\
h_{3}(y)=A_{3}^{*} h(y) & \text { at 3rd stress level } \\
\vdots & \\
h_{j}(y)=A_{j}^{*} h(y) & \text { at } j \text { th stress level } \\
\vdots & \\
h_{m}(y)=A_{m}^{*} h(y) & \text { at } m \text { th stress level, }
\end{array}\right.
$$

where $A_{m}^{*}>A_{m-1}^{*}>\cdots>A_{1}^{*}>1$. Thus, $h(y)<h_{1}(y)<$ $h_{2}(y)<\cdots<h_{m}(y)$.

4.1. Life Distribution under TFR Model. Therefore, the pdf and cdf of TFR model when underlying life distribution is Burr type XII are given by

$$
g_{Y}(y)=\left(\frac{k c}{\alpha}\right) \cdot\left(\frac{y}{\alpha}\right)^{c-1} \cdot\left(1+\left(\frac{y}{\alpha}\right)^{c}\right)^{-(k+1)},
$$

under normal condition,

$$
\begin{aligned}
& g_{X_{i}}(y) \\
& =\left(\frac{k \prod_{j=1}^{i} A_{j} c}{\alpha}\right) \cdot\left(\frac{x_{i}}{\alpha}\right)^{c-1} \cdot\left(1+\left(\frac{x_{i}}{\alpha}\right)^{c}\right)^{-\left(k \prod_{j=1}^{i} A_{j}+1\right)},
\end{aligned}
$$

under $i$ th accelerated condition, $i=1,2, \ldots, m$,

$$
G_{Y}(y)=1-\left(1+\left(\frac{y}{\alpha}\right)^{c}\right)^{-k}
$$

under normal condition,

$$
G_{X_{i}}(y)=1-\left(1+\left(\frac{x_{i}}{\alpha}\right)^{c}\right)^{-k \prod_{j=1}^{i} A_{j}},
$$

under $i$ th accelerated condition, $i=1,2, \ldots, m$.

In this paper, we have taken three test chambers; that is, $m+$ $1=3$.

\section{Lot Acceptance Sampling Procedure}

Assume that one-sided lower specification limit $L$ exists for the lifetime of a product. Let for convenience $T=\ln Y$, instead of using the actual life time $Y$. The lower specification limit on $T$ is $L^{\prime}=\ln L$. Then, pdf and cdf of an item tested at normal operating condition and at accelerated conditions using $g_{Y}(y), g_{X_{i}}(y), G_{Y}(y)$, and $G_{X_{i}}(y)$ in Section 4.1 are given by

$$
f_{T}\left(t ; A_{1}, A_{2}, \alpha, c, k\right)=\frac{k e^{((t-\mu) / \sigma)}}{\left(\sigma\left(1+e^{((t-\mu) / \sigma)}\right)^{(k+1)}\right)}
$$

under normal condition

$$
\begin{gathered}
f_{T_{1}}\left(t_{1} ; A_{1}, A_{2}, \alpha, c, k\right)=\frac{k A_{1} e^{\left(\left(t_{1}-\mu\right) / \sigma\right)}}{\left(\sigma\left(1+e^{\left(\left(t_{1}-\mu\right) / \sigma\right)}\right)^{\left(k A_{1}+1\right)}\right)} \\
\text { at 1st stress level } \\
f_{T_{2}}\left(t_{2} ; A_{1}, A_{2}, \alpha, c, k\right)=\frac{k A_{1} A_{2} e^{\left(\left(t_{2}-\mu\right) / \sigma\right)}}{\left(\sigma\left(1+e^{\left(\left(t_{2}-\mu\right) / \sigma\right)}\right)^{\left(k A_{1} A_{2}+1\right)}\right)}
\end{gathered}
$$

at 2 nd stress level,

$$
F_{T}\left(t ; A_{1}, A_{2}, \alpha, c, k\right)=1-\left(1+e^{((t-\mu) / \sigma)}\right)^{-k}
$$

under normal condition

$$
F_{T_{1}}\left(t_{1} ; A_{1}, A_{2}, \alpha, c, k\right)=1-\left(1+e^{\left(\left(t_{1}-\mu\right) / \sigma\right)}\right)^{-k A_{1}}
$$

at 1 st stress level

$$
F_{T_{2}}\left(t_{2} ; A_{1}, A_{2}, \alpha, c, k\right)=1-\left(1+e^{\left(\left(t_{2}-\mu\right) / \sigma\right)}\right)^{-k A_{1} A_{2}}
$$

at 2 nd stress level. 
The reliability function of an item tested at normal and accelerated conditions $A_{1}^{*}$ and $A_{2}^{*}$ are, respectively, given by

$$
\bar{F}_{T}\left(t ; A_{1}, A_{2}, \alpha, c, k\right)=\left(1+e^{((t-\mu) / \sigma)}\right)^{-k}
$$

under used condition

$$
\bar{F}_{T_{1}}\left(t_{1} ; A_{1}, A_{2}, \alpha, c, k\right)=\left(1+e^{\left(\left(t_{1}-\mu\right) / \sigma\right)}\right)^{-k A_{1}}
$$

at 1 st stress level

$$
\bar{F}_{T_{2}}\left(t_{2} ; A_{1}, A_{2}, \alpha, c, k\right)=\left(1+e^{\left(\left(t_{2}-\mu\right) / \sigma\right)}\right)^{-k A_{1} A_{2}}
$$

at 2 nd stress level,

where $\mu=\ln (\alpha)$ is location parameter and $\sigma=(c)^{-1}$.

The following lot acceptance sampling procedure is considered.

(i) Samples of $n$ items are randomly selected from the lot and are tested according to the above test procedure.

(ii) Maximum likelihood estimators (MLEs) $\widehat{\mu}$ and $\widehat{\sigma}$, respectively, of location parameter $\mu$ and scale parameter $\sigma$ at normal operating condition, respectively, of Burr type XII distribution are obtained from the test data.

(iii) Schneider's [9] approach to $k$-method is used wherein sample mean and standard deviation are replaced by MLEs of location parameter and scale parameter of $\log$ life distribution, respectively. In this paper $k_{1}$ instead of $k$ has been used as acceptability constant. The value of test statistic $T^{\prime}=\widehat{\mu}-k_{1} \widehat{\sigma}$ is compared with $L^{\prime}$; the lot is accepted if $T^{\prime} \geq L^{\prime}$ and rejected otherwise. The sample size $n$ and acceptability constant $k_{1}$ determined using variance optimality criterion subject to the constraints that the lots with fraction nonconforming $p \leq p_{\widetilde{\alpha}}$ are accepted with probability of at least $1-\tilde{\alpha}$ and lots with $p>p_{\tilde{\beta}}$ are rejected with probability of at least $1-\tilde{\beta}$.

\section{Model Formulation}

Maximum likelihood method has been used to estimate the model parameters $\alpha, c$, and acceleration factors, $A_{1}$ and $A_{2}$, from the test data.

6.1. Likelihood Function. The likelihood function based on " $n$ " observation is

$$
\begin{aligned}
L \equiv & L\left(\alpha, c, A_{1}, A_{2}\right) \\
= & \prod_{i=1}^{n \phi_{1}} L_{u_{i}}\left(\alpha, c ;\left(t_{i}, \delta_{u_{i}}\right)\right) \cdot \prod_{j=1}^{n \phi_{2}} L_{a_{1 j}}\left(\alpha, c, A_{1} ;\left(t_{1 j}, \delta_{a_{1 j}}\right)\right) \\
& \cdot \prod_{k=1}^{n \phi_{3}} L_{a_{2 k}}\left(\alpha, c, A_{1}, A_{2} ;\left(t_{2 j}, \delta_{a_{2 j}}\right)\right),
\end{aligned}
$$

where

$$
L_{u_{i}} \equiv L_{u_{i}}\left(\alpha, c ;\left(t_{i}, \delta_{u_{i}}\right)\right)
$$$$
=\frac{k e^{\left(t_{i}-\mu\right) / \sigma}}{\left(\sigma\left(1+e^{t_{i}-\mu / \sigma}\right)^{k+1}\right)} \cdot\left(\left(1+e^{\left(\eta^{\prime}-\mu\right) / \sigma}\right)^{-k}\right)^{\bar{\delta}_{u_{i}}},
$$$$
L_{a_{1 j}} \equiv L_{a_{1 j}}\left(\alpha, c, A_{1} ;\left(t_{1 j}, \delta_{a_{1 j}}\right)\right)
$$$$
=\left(\frac{k A_{1} e^{\left(t_{1 j}-\mu\right) / \sigma}}{\left(\sigma\left(1+e^{\left(t_{1 j}-\mu\right) / \sigma}\right)^{k A_{1}+1}\right)}\right)^{\delta_{a_{1 j}}}
$$$$
\cdot\left(\left(1+e^{\left(\eta^{\prime}-\mu\right) / \sigma}\right)^{-k A_{1}}\right)^{\bar{\delta}_{a_{1 j}}}
$$

$$
L_{a_{2 j}} \equiv L_{a_{2 j}}\left(\alpha, c, A_{1}, A_{2} ; t_{2 j}, \delta_{a_{2 j}}\right)
$$

$$
=\left(\frac{k A_{1} A_{2} e^{\left(t_{2 j}-\mu\right) / \sigma}}{\left(\sigma\left(1+e^{\left(t_{2 j}-\mu\right) / \sigma}\right)^{k A_{1} A_{2}+1}\right)}\right)^{\delta_{a_{2 j}}}
$$$$
\cdot\left(\left(1+e^{\left(\eta^{\prime}-\mu\right) / \sigma}\right)^{-k A_{1} A_{2}}\right)^{\bar{\delta}_{a_{2 j}}}
$$

$$
\bar{\delta}_{u_{i}}=1-\delta_{u_{i}}, \quad \bar{\delta}_{a_{1 j}}=1-\delta_{a_{1 j}}, \quad \bar{\delta}_{a_{2 k}}=1-\delta_{a_{2 k}} .
$$

The first-order partial derivatives of log-likelihood function of the $i$ th unit with respect to $A_{1}, A_{2}, \alpha$, and $c$ are given by

$$
\begin{aligned}
& \frac{\partial \ln L_{u_{i}}}{\partial A_{1}}=0, \\
& \frac{\partial \ln L_{u_{i}}}{\partial A_{2}}=0, \\
& \begin{aligned}
\frac{\partial \ln L_{u_{i}}}{\partial \alpha}=-\left(\frac{c}{\alpha}\right) \cdot\left\{\delta_{u_{i}}\left(1-\left(\frac{(k+1) e^{\left(t_{i}-\mu\right) / \sigma}}{\left(1+e^{\left(t_{i}-\mu\right) / \sigma}\right)}\right)\right)\right. \\
\left.\quad-\bar{\delta}_{u_{i}}\left(\frac{k e^{\left(\eta^{\prime}-\mu\right) / \sigma}}{\left(1+e^{\left(\eta^{\prime}-\mu\right) / \sigma}\right)}\right)\right\},
\end{aligned}
\end{aligned}
$$




$$
\begin{aligned}
& \frac{\partial \ln L_{u_{i}}}{\partial c}=\left(\frac{1}{c}\right) \cdot\left\{\delta _ { u _ { i } } \left(1+\left(\frac{\left(t_{i}-\mu\right)}{\sigma}\right)\right.\right. \\
& \left.-\left(\frac{(k+1)\left(\left(t_{i}-\mu\right) / \sigma\right) e^{\left(t_{i}-\mu\right) / \sigma}}{\left(1+e^{\left(t_{i}-\mu\right) / \sigma}\right)}\right)\right) \\
& \left.-\bar{\delta}_{u_{i}}\left(\frac{k\left(\left(\eta^{\prime}-\mu\right) / \sigma\right) e^{\left(\eta^{\prime}-\mu\right) / \sigma}}{\left(1+e^{\left(\eta^{\prime}-\mu\right) / \sigma}\right)}\right)\right\}, \\
& \frac{\partial \ln L_{a_{1 j}}}{\partial A_{1}}=\delta_{a_{1 j}}\left(\left(\frac{1}{A_{1}}\right)-k \ln \left(1+e^{\left(k_{1 j}-\mu\right) / \sigma}\right)\right) \\
& -\bar{\delta}_{a_{1 j}}\left(k \ln \left(1+e^{\left(\eta^{\prime}-\mu\right) / \sigma}\right)\right)
\end{aligned}
$$$$
\frac{\partial \ln L_{a_{1 j}}}{\partial A_{2}}=0
$$$$
\begin{gathered}
\frac{\partial \ln L_{a_{1 j}}}{\partial \alpha}=-\left(\frac{c}{\alpha}\right) \cdot\left\{\delta_{a_{1 j}}\left(1-\left(\frac{\left(k A_{1}+1\right) e^{\left(t_{1 j}-\mu\right) / \sigma}}{\left(1+e^{\left(t_{1 j}-\mu\right) / \sigma}\right)}\right)\right)\right. \\
\left.-\bar{\delta}_{a_{1 j}}\left(\frac{k A_{1} e^{\left(\eta^{\prime}-\mu\right) / \sigma}}{\left(1+e^{\left(\eta^{\prime}-\mu\right) / \sigma}\right)}\right)\right\},
\end{gathered}
$$$$
\frac{\partial \ln L_{a_{1 j}}}{\partial c}=\left(\frac{1}{c}\right) \cdot\left\{\delta _ { a _ { 1 j } } \left(1+\left(\frac{\left(t_{1 j}-\mu\right)}{\sigma}\right)\right.\right.
$$$$
\left.-\left(\frac{\left(k A_{1}+1\right)\left(\left(t_{1 j}-\mu\right) / \sigma\right) e^{\left(t_{1 j}-\mu\right) / \sigma}}{\left(1+e^{\left(t_{1 j}-\mu\right) / \sigma}\right)}\right)\right)
$$$$
\left.-\bar{\delta}_{a_{1 j}}\left(\frac{k A_{1}\left(\left(\eta^{\prime}-\mu\right) / \sigma\right) e^{\left(\eta^{\prime}-\mu\right) / \sigma}}{\left(1+e^{\left(\eta^{\prime}-\mu\right) / \sigma}\right)}\right)\right\},
$$

$$
\begin{aligned}
\frac{\partial \ln L_{a_{2 j}}}{\partial A_{1}}=\delta_{a_{2 j}} & \left(\left(\frac{1}{A_{1}}\right)-k A_{2} \ln \left(1+e^{\left(t_{2 j}-\mu\right) / \sigma}\right)\right) \\
& -\bar{\delta}_{a_{2 j}}\left(k A_{2} \ln \left(1+e^{\left(\eta^{\prime}-\mu\right) / \sigma}\right)\right),
\end{aligned}
$$

$$
\begin{aligned}
\frac{\partial \ln L_{a_{2 j}}}{\partial A_{2}}=\delta_{a_{2 j}} & \left(\left(\frac{1}{A_{2}}\right)-k A_{1} \ln \left(1+e^{\left(t_{2 j}-\mu\right) / \sigma}\right)\right) \\
& -\bar{\delta}_{a_{2 j}}\left(k A_{1} \ln \left(1+e^{\left(\eta^{\prime}-\mu\right) / \sigma}\right)\right),
\end{aligned}
$$$$
\frac{\partial \ln L_{a_{2 j}}}{\partial \alpha}=-\left(\frac{c}{\alpha}\right) \cdot\left\{\delta_{a_{2 j}}\left(1-\left(\frac{\left(k A_{1} A_{2}+1\right) e^{\left(t_{2 j}-\mu\right) / \sigma}}{\left(1+e^{\left(t_{2 j}-\mu\right) / \sigma}\right)}\right)\right)\right.
$$$$
\left.-\bar{\delta}_{a_{2 j}}\left(\frac{k A_{1} A_{2} e^{\left(\eta^{\prime}-\mu\right) / \sigma}}{\left(1+e^{\left(\eta^{\prime}-\mu\right) / \sigma}\right)}\right)\right\}
$$

$\frac{\partial \ln L_{a_{2 j}}}{\partial c}=\left(\frac{1}{c}\right)$

$$
\begin{aligned}
& \left\{\delta _ { a _ { 2 j } } \left(1+\left(\frac{\left(t_{2 j}-\mu\right)}{\sigma}\right)\right.\right. \\
& \left.-\left(\frac{\left(k A_{1} A_{2}+1\right)\left(\left(t_{2 j}-\mu\right) / \sigma\right) e^{\left(t_{2 j}-\mu\right) / \sigma}}{\left(1+e^{\left(\eta^{\prime}-\mu\right) / \sigma}\right)}\right)\right) \\
& \left.-\bar{\delta}_{a_{2 j}}\left(\frac{k A_{1} A_{2}\left(\left(\eta^{\prime}-\mu\right) / \sigma\right) e^{\left(\eta^{\prime}-\mu\right) / \sigma}}{\left(1+e^{\left(\eta^{\prime}-\mu\right) / \sigma}\right)}\right)\right\} .
\end{aligned}
$$

On summing these partial derivatives and equating them to zero, likelihood equations are obtained. Since the closed form solutions of above likelihood equations are very hard to obtain, so further numerical treatment is required to obtain the MLEs of $A_{1}, A_{2}, \alpha$, and $c$.

6.2. Fisher Information Matrix. The Fisher information matrix $F\left(A_{1}, A_{2}, \alpha, c\right) \equiv F$ is the $4 \times 4$ symmetric matrix of expectation of negative second-order partial derivatives of the $\log$ likelihood function with respect to $A_{1}, A_{2}, \alpha$, and $c$. Consider

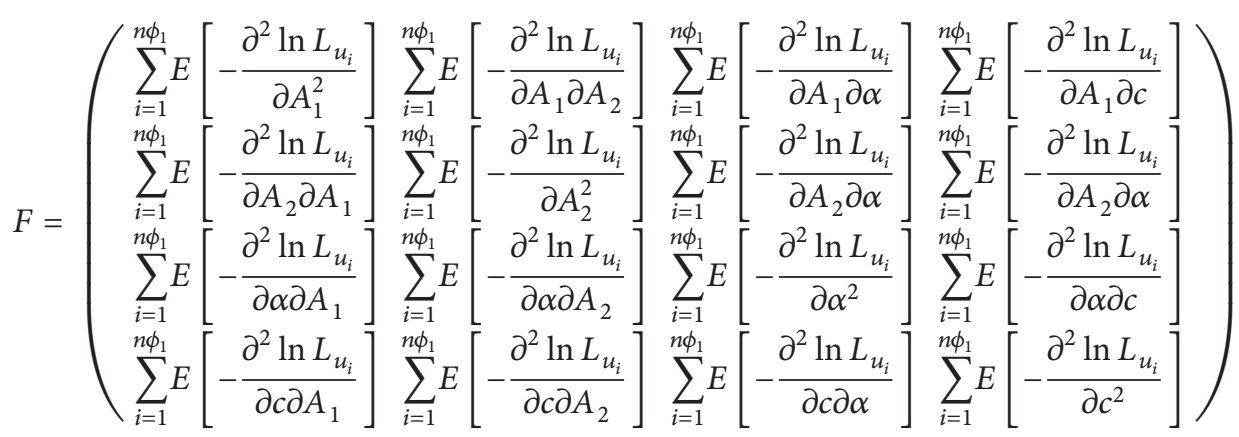




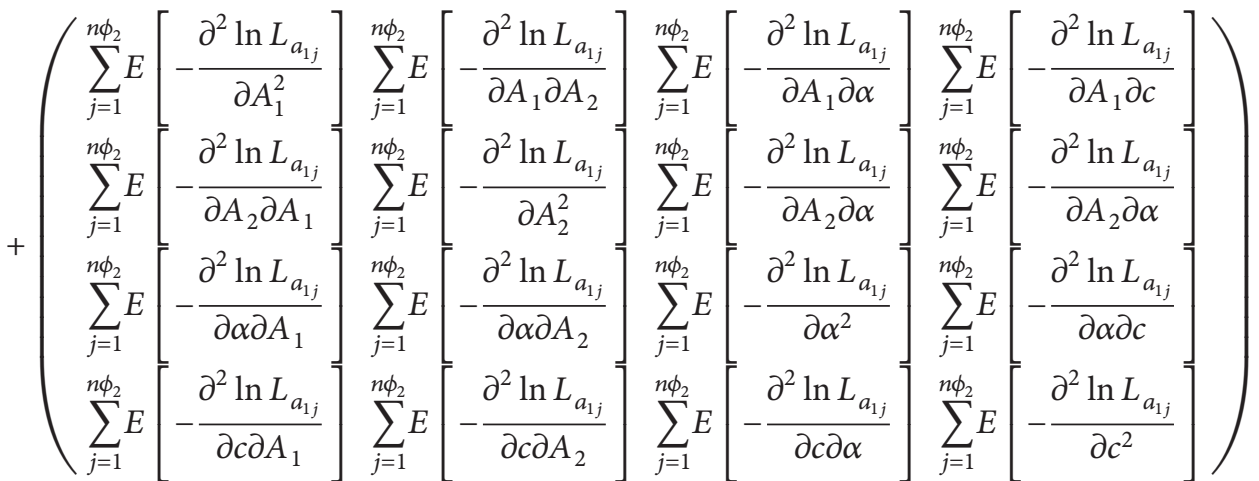

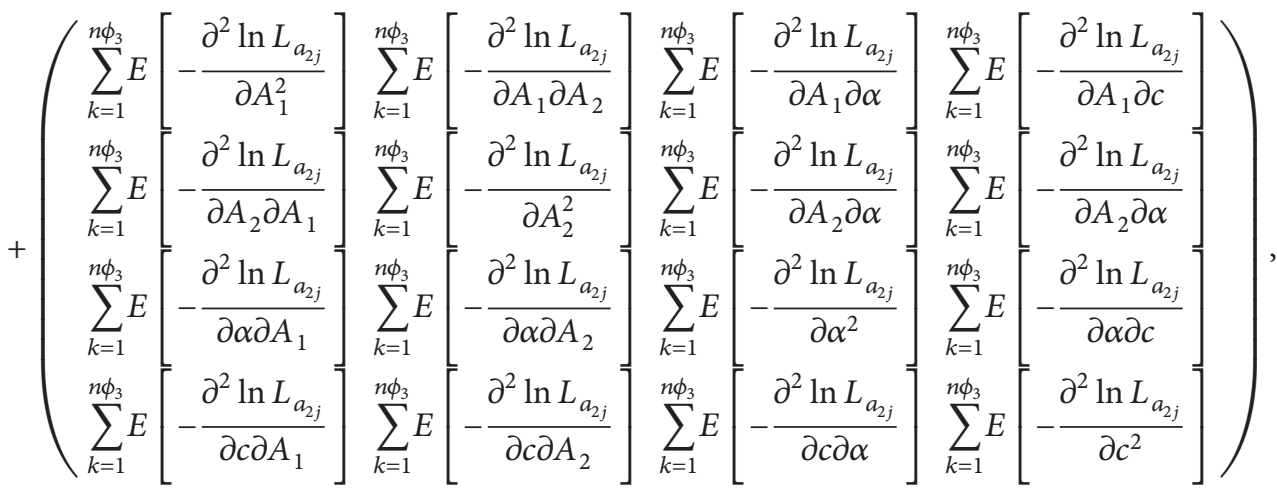

where the values of these elements are given in Appendix A.

6.3. Asymptotic Variance of Test Statistic $T^{\prime}$. For any plan, the asymptotic variance-covariance matrix of the MLEs $\widehat{A}_{1}, \widehat{A}_{2}$, $\widehat{\alpha}, \widehat{c}$ is the inverse of the corresponding Fisher information matrix; that is,

$$
\sum=F^{-1}=\left[\begin{array}{cccc}
\operatorname{Asvar}\left(\widehat{A}_{1}\right) & \operatorname{Ascov}\left(\widehat{A}_{1}, \widehat{A}_{2}\right) & \operatorname{Ascov}\left(\widehat{A}_{1}, \widehat{\alpha}\right) & \operatorname{Ascov}\left(\widehat{A}_{1}, \widehat{c}\right) \\
\operatorname{Ascov}\left(\widehat{A}_{2}, \widehat{A}_{1}\right) & \operatorname{Asvar}\left(\widehat{A}_{2}\right) & \operatorname{Ascov}\left(\widehat{A}_{2}, \widehat{\alpha}\right) & \operatorname{Ascov}(\widehat{A}, \widehat{c}) \\
\operatorname{Ascov}\left(\widehat{\alpha}, \widehat{A}_{1}\right) & \operatorname{Ascov}\left(\widehat{\alpha}, \widehat{A}_{2}\right) & \operatorname{Asvar}(\widehat{\alpha}) & \operatorname{Ascov}(\widehat{\alpha}, \widehat{c}) \\
\operatorname{Ascov}\left(\widehat{c}, \widehat{A}_{1}\right) & \operatorname{Ascov}\left(\widehat{c}, \widehat{A}_{2}\right) & \operatorname{Ascov}(\widehat{c}, \widehat{\alpha}) & \operatorname{Asvar}(\widehat{c})
\end{array}\right]
$$

The asymptotic variance of the test statistic $T^{\prime}$ is given by

$$
\begin{aligned}
& \operatorname{Asvar}\left(T^{\prime}\right) \\
& =\operatorname{Asvar}\left(\widehat{\mu}_{0}\right)-2 k_{1} \operatorname{Ascov}\left(\widehat{\mu}_{0}, \widehat{\sigma}_{0}\right)+k_{1}^{2} \operatorname{Asvar}\left(\widehat{\sigma}_{0}\right)=\frac{V}{n},
\end{aligned}
$$

where $V$ is obtained in Appendix B.

\section{OC Curve}

The operating characteristic (OC) curve measures the performance of a sampling plan and plots the probability of accepting the lot versus the proportion nonconforming of the lot. Based on the asymptotic distribution theory,

$$
\frac{\left(T^{\prime}-\left(\mu-k_{1} \sigma\right)\right)}{\sqrt{\operatorname{AsVar}\left[T^{\prime}\right]}} \sim N(0,1) \quad \text { as } n \longrightarrow \infty .
$$

The standardized variate using (14) is

$$
U=\frac{\left(T^{\prime}-\left(\mu-k_{1} \sigma\right)\right) \sqrt{n}}{\sqrt{V}} \sim N(0,1) \text { as } n \longrightarrow \infty .
$$

The OC curve is obtained by plotting the probability of accepting the lot, $L_{p}$, given as

$$
L_{p}=\operatorname{Pr}\left[T^{\prime} \geq L^{\prime}\right]=1-\Phi\left[\frac{\sigma\left(u_{p}+k_{1}\right) \sqrt{n}}{\sqrt{V}}\right]
$$


against the fraction nonconforming, $p$, where $u_{p}=\left(L^{\prime}-\right.$ $\mu) / \sigma$ is the quantile of the standard logistic distribution corresponding to the fraction nonconforming $p$, and $\Phi(\cdot)$ is the standard normal distribution function. Therefore, the following equations have to be solved for $k_{1}^{*}$ and $n^{*}$ in order to obtain an optimal sampling plan for two given points $\left(p_{\tilde{\alpha}}, 1-\widetilde{\alpha}\right)$ and $\left(p_{\widetilde{\beta}}, \widetilde{\beta}\right)$ on the OC curve,

$$
\begin{gathered}
z_{\tilde{\alpha}}-\frac{\left(\sigma\left(u_{P_{\tilde{\alpha}}}+k_{1}\right)\right) \sqrt{n}}{\sqrt{V}}=0, \\
z_{1-\tilde{\beta}}-\frac{\left(\sigma\left(u_{P_{\tilde{\beta}}}+k_{1}\right)\right) \sqrt{n}}{\sqrt{V}}=0,
\end{gathered}
$$

where $u_{P_{\tilde{\alpha}}}$ and $u_{P_{\tilde{\beta}}}$ denote the quantiles of the standard normal distribution and $z_{\widetilde{\alpha}}$ and $z_{1-\tilde{\beta}}$ are the quantiles of the standard log-life distribution. Thus, on solving (18),

$$
\begin{gathered}
k_{1}^{*}=\frac{\left(z_{1-\tilde{\beta}} u_{P_{\tilde{\alpha}}}-z_{\tilde{\alpha}} u_{P_{\tilde{\beta}}}\right)}{\left(z_{\tilde{\alpha}}-z_{1-\tilde{\beta}}\right)}, \\
n^{*}=\frac{\left(k_{2} V\right)}{\sigma^{2}},
\end{gathered}
$$

where

$$
k_{2}=\frac{\left(z_{\widetilde{\alpha}}-z_{1-\widetilde{\beta}}\right)}{\left(u_{P_{\widetilde{\alpha}}}-u_{P_{\widetilde{\beta}}}\right)}
$$

and $V$ is given in (14).

See Schneider [9] for reference.

\section{Formulation of an Optimization Problem}

$V$ in (14) is a function of $A_{1}, A_{2}, \eta, \alpha, c$, and $k$. Thus, the optimal design problem can be formulated as a nonlinear optimization problem:

$$
\begin{array}{ll}
\text { Minimize } & V \\
\text { subject to } & 0<\phi_{i}<1, \quad i=1,2,3, \\
& \sum_{i=1}^{3} \phi_{i}=1 \\
& \phi_{i} p_{i} \geq 0.1, \quad i=1,2,3 .
\end{array}
$$

Since the sample size is unknown while minimizing $V$, therefore instead of giving minimum mean number of failures (MMNF) a prespecified value in advance, 0.1, is assigned to the ratio of MMNF and the sample size at each stress level. Another suitable number for MMNF can be specified according to cost, time, and precision implications (see Yang [2]). The optimum values of $\phi_{i}, i=1,2,3$, are found by minimizing $V$ under type I censoring, using NMinimize option of Mathematica 8.
TABLE 1: Change in $\left(\phi_{i}{ }^{*}, n^{*}\right), i=1,2,3$ for different values of $A_{1}$ $\left(A_{2}=3, \eta=5, \alpha=0.9, c=3.5\right.$, and $\left.k=4\right)$.

\begin{tabular}{lcccc}
\hline$A_{1}$ & $\phi_{1}{ }^{*}$ & $\phi_{2}{ }^{*}$ & $\phi_{3}{ }^{*}$ & $n^{*}$ \\
\hline 1.5 & 0.29387 & 0.33916 & 0.36697 & $37.2889 \approx 37$ \\
1.6 & 0.23162 & 0.23576 & 0.53262 & $36.6683 \approx 37$ \\
1.7 & 0.19098 & 0.21097 & 0.59805 & $35.8638 \approx 36$ \\
1.8 & 0.1584 & 0.20729 & 0.63431 & $35.1254 \approx 35$ \\
1.9 & 0.13196 & 0.21318 & 0.65486 & $34.5078 \approx 35$ \\
2 & 0.11085 & 0.22402 & 0.66513 & $34.0173 \approx 34$ \\
\hline
\end{tabular}

\section{A Numerical Example}

In this section, a hypothetical constant-stress PALTSP experiment is considered to illustrate the methods described in this paper.

9.1. OC Curve. Choose two points $\left(p_{\tilde{\alpha}}, 1-\widetilde{\alpha}\right)$ and $\left(p_{\widetilde{\beta}}, \widetilde{\beta}\right)$ on the OC curve as $(0.01,0.99)$ and $(0.10,0.10)$, respectively.

9.2. Optimal Lot Acceptability Constant. Compute the acceptability constant $k_{1}$, using (19).

Since $z_{\widetilde{\alpha}}=-2.32635, z_{1-\tilde{\beta}}=1.28155, u_{P_{\widetilde{\alpha}}}=-5.98519$, and $u_{P_{\tilde{\beta}}}=-3.62346$, we have $k_{1}=((1.28155(-5.98519))-$ $((-3.62346)(-2.32635))) /((-2.32635)-(1.28155))=$ 4.46236 .

9.3. Optimal Plan. Optimal $\phi_{i}^{*}, i=1,2,3$, and $n^{*}$ are using (22). These are given in Table 1 using the following hypothetical data set:

$$
\begin{array}{ll}
A_{1}=1.5, & A_{2}=3, \quad \eta=5, \\
\alpha=0.9, & c=3.5, \quad k=4 .
\end{array}
$$

Table 1 shows that optimal sample size decreases as $A_{1}$ increases and optimal sample proportions allocated to accelerated condition $A_{2}$ increase as $A_{1}$ increases.

9.4. Optimal Acceptance Sampling Plan. Let us consider the lower specification limit of $L$ as $L^{\prime}(\ln L)$ indicating that items with lifetime shorter than $\ln L$ are nonconforming. For given lower specification limit $L^{\prime}$, lot is accepted if $T^{\prime}=\widehat{\mu}_{0}-k_{1} \widehat{\sigma}_{0}>$ $L^{\prime}$, lot is accepted and otherwise rejected.

Figure 1 depicts the OC curve obtained from $u_{P}, V, n^{*}$ and the two points $\left(p_{\widetilde{\alpha}}, 1-\widetilde{\alpha}\right)$ and $\left(p_{\widetilde{\beta}}, \widetilde{\beta}\right)$.

Tables 2 and 3 present optimum sampling plan for various values of $p_{\widetilde{\alpha}}$ and $p_{\widetilde{\beta}}$ when $(1-\widetilde{\alpha}, \widetilde{\beta})=(0.95,0.10)$ and $(0.99,0.01)$. It is observed that for given $p_{\widetilde{\alpha}}$ as $p_{\widetilde{\beta}}$ increases optimal " $n$ "” decreases, optimal $\phi_{1}^{*}$ increases, and optimal $\phi_{2}^{*}$ and optimal $\phi_{3}^{*}$ decrease. Using the data in Table 2, Figures 2 and 3 depict the OC curve obtained from the two points $\left(p_{\tilde{\alpha}}, 1-\widetilde{\alpha}\right)$ as $(0.001,0.95),(0.01,0.95)$ and $\left(p_{\widetilde{\beta}}, \widetilde{\beta}\right)$ as $(0.01,0.10),(0.05,0.10),(0.10,0.10) ;(0.05,0.10),(0.01,0.10)$, $(0.15,0.10)$, respectively. In a similar manner, data in Table 3 


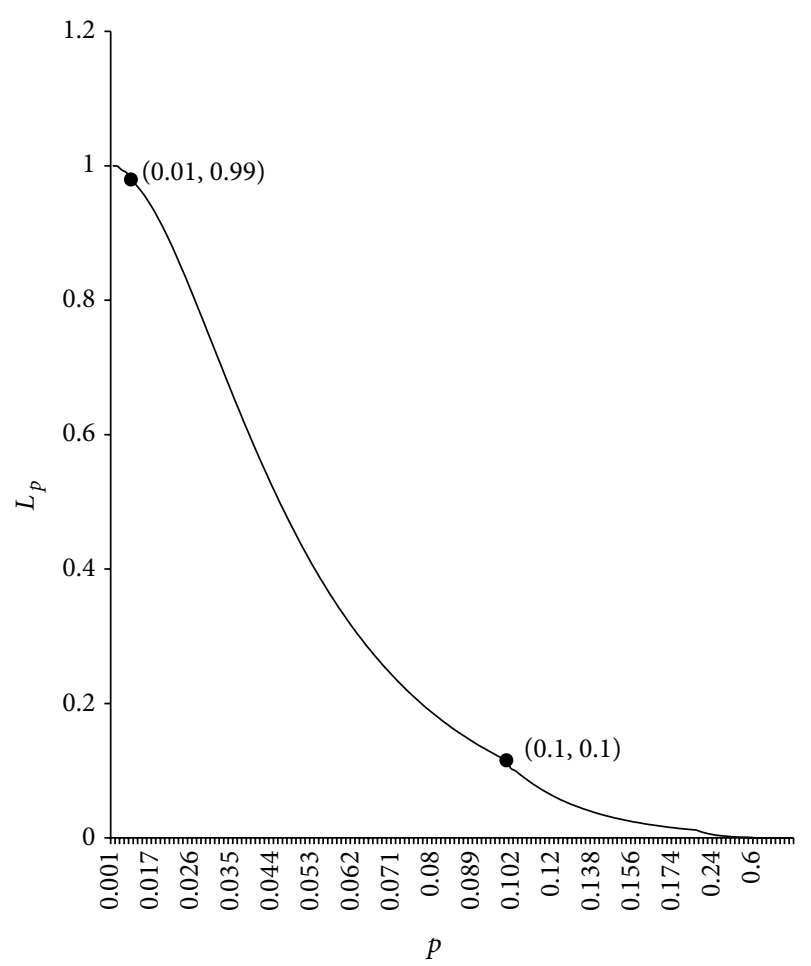

FIgURE 1: OC curve with $\left(p_{\tilde{\alpha}}, 1-\widetilde{\alpha}\right)$ as $(0.01,0.99)$ and $\left(p_{\tilde{\beta}}, \widetilde{\beta}\right)$ as $(0.10,0.10)$.

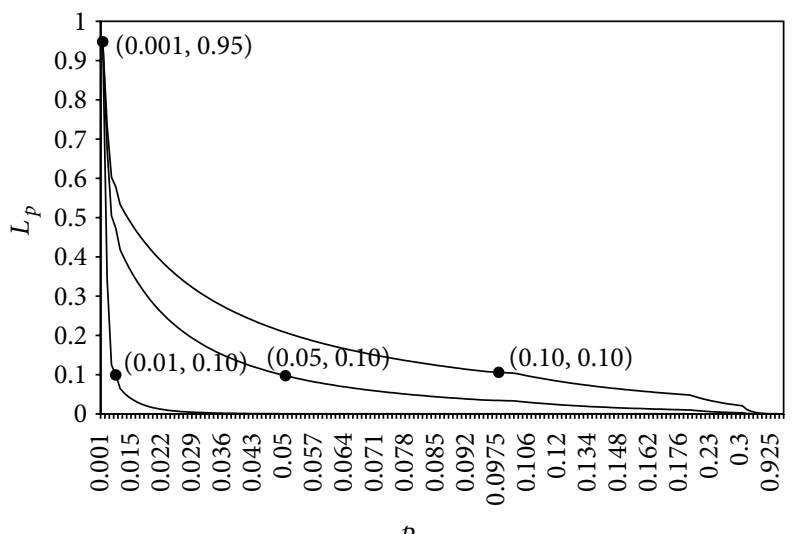

Figure 2: OC curves for $\left(p_{\tilde{\alpha}}, 1-\widetilde{\alpha}\right)$ as $(0.001,0.95)$ and $\left(p_{\tilde{\beta}}, \widetilde{\beta}\right)$ as $(0.01,0.10),(0.05,0.10)$, and $(0.10,0.10)$.

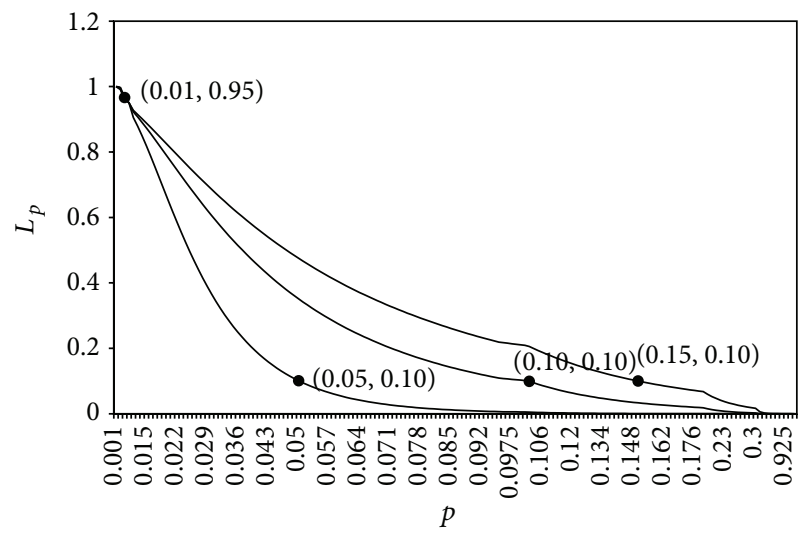

Figure 3: OC curves for $\left(p_{\tilde{\alpha}}, 1-\widetilde{\alpha}\right)$ as $(0.01,0.95)$ and $\left(p_{\tilde{\beta}}, \widetilde{\beta}\right)$ as $(0.05$, $0.10),(0.10,0.10)$, and $(0.15,0.10)$.

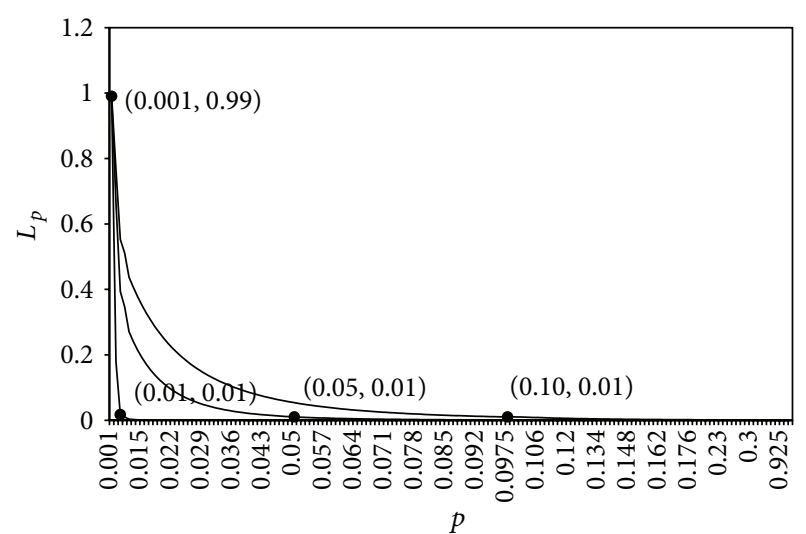

Figure 4: OC curves for $\left(p_{\tilde{\alpha}}, 1-\widetilde{\alpha}\right)$ as $(0.001,0.99)$ and $\left(p_{\tilde{\beta}}, \widetilde{\beta}\right)$ as $(0.01,0.01),(0.05,0.01)$, and $(0.10,0.01)$.

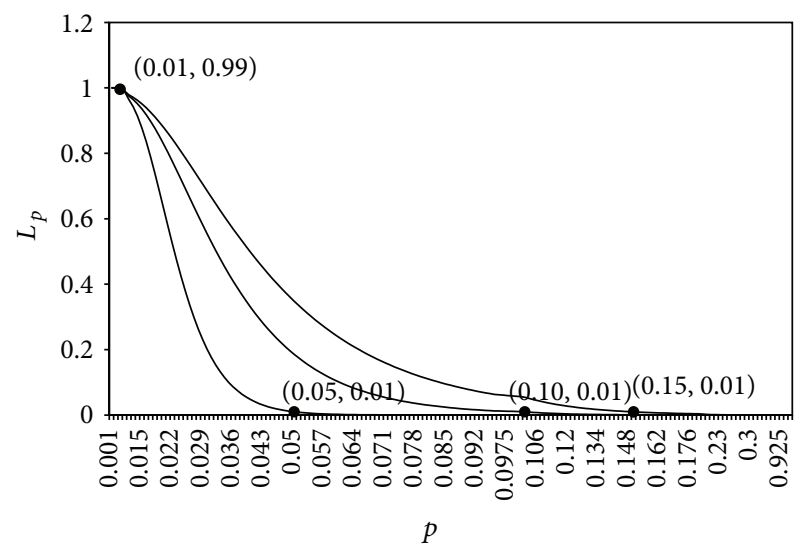

Figure 5: OC curves for $\left(p_{\tilde{\alpha}}, 1-\widetilde{\alpha}\right)$ as $(0.01,0.99)$ and $\left(p_{\widetilde{\beta}}, \widetilde{\beta}\right)$ as $(0.05$, $0.01),(0.10,0.01)$, and $(0.15,0.01)$.

has been used in plotting OC curve in Figures 4 and 5 by taking $1-\tilde{\alpha}$ as 0.99 and $\widetilde{\beta}$ as 0.01 .

\section{Sensitivity Analysis}

To formulate an optimum sampling plan, the information about acceleration factors $A_{1}$ and parameters of the model $\alpha$ and $c$ is needed as incorrect choice of these results in poor estimates of the parameters. The effects of incorrect preestimates of $A_{1}, A_{2}, \alpha$, and $c$ in terms of the relative increase in asymptotic variance of test statistic have been studied. The percentage deviations (PD) of the resulting optimal settings are measured by $\mathrm{PD}=\left(\left|V^{* *}-V^{*}\right| / V^{*}\right) \times$ 100 , where $V^{*}$ is the setting obtained with the given design parameters, and $V^{* *}$ is the one obtained when the parameter is misspecified. Tables 4 and 5 show that irrespective of whether the incorrect variance is smaller or larger than the true variance, the proposed optimum plan is robust since the percentage deviation in variance is small. 
TABLE 2: Effects of various values of $\left(p_{\tilde{\alpha}}, 1-\widetilde{\alpha}\right)$ and $\left(p_{\tilde{\beta}}, \widetilde{\beta}\right)$ on optimal ALT plans $\left(A_{1}=1.5, A_{2}=3, \eta=5, \alpha=0.9, c=3.5\right.$, and $\left.k=4\right)$.

\begin{tabular}{|c|c|c|c|c|c|c|c|c|}
\hline \multicolumn{9}{|c|}{$1-\widetilde{\alpha}=0.95, \widetilde{\beta}=0.10$} \\
\hline$p_{\widetilde{\alpha}}$ & $p_{\tilde{\beta}}$ & $k_{1}$ & $k_{2}$ & $\mathrm{~V}^{*}$ & $\phi_{1}{ }^{*}$ & $\phi_{2}{ }^{*}$ & $\phi_{3}{ }^{*}$ & $n^{*}$ \\
\hline \multirow{3}{*}{0.001} & 0.01 & 6.99603 & 1.60734 & 3.27656 & 0.16048 & 0.40322 & 0.43630 & 65 \\
\hline & 0.05 & 6.07697 & 0.55073 & 2.45800 & 0.19573 & 0.38629 & 0.41798 & 17 \\
\hline & 0.1 & 5.66856 & 0.39268 & 2.13194 & 0.21515 & 0.37697 & 0.40789 & 10 \\
\hline \multirow{3}{*}{0.01} & 0.05 & 5.06613 & 3.20311 & 1.69332 & 0.24966 & 0.36039 & 0.38995 & 66 \\
\hline & 0.1 & 4.65773 & 1.53536 & 1.42466 & 0.27827 & 0.34665 & 0.37508 & 27 \\
\hline & 0.15 & 4.41008 & 1.09052 & 1.27305 & 0.29829 & 0.33703 & 0.36468 & 17 \\
\hline
\end{tabular}

TABLE 3: Effects of various values of $\left(p_{\tilde{\alpha}}, 1-\widetilde{\alpha}\right)$ and $\left(p_{\tilde{\beta}}, \widetilde{\beta}\right)$ on optimal ALT plans $\left(A_{1}=1.5, A_{2}=3, \eta=5, \alpha=0.9, c=3.5\right.$, and $\left.k=4\right)$.

\begin{tabular}{|c|c|c|c|c|c|c|c|c|}
\hline \multicolumn{9}{|c|}{$1-\widetilde{\alpha}=0.99, \widetilde{\beta}=0.01$} \\
\hline$p_{\widetilde{\alpha}}$ & $p_{\widetilde{\beta}}$ & $k_{1}$ & $k_{2}$ & $\mathrm{~V}^{*}$ & $\phi_{1}{ }^{*}$ & $\phi_{2}{ }^{*}$ & $\phi_{3}{ }^{*}$ & $n^{*}$ \\
\hline \multirow{3}{*}{0.001} & 0.01 & 7.13931 & 4.06301 & 3.41476 & 0.15582 & 0.40546 & 0.43872 & 170 \\
\hline & 0.05 & 6.32175 & 1.39212 & 2.66454 & 0.18532 & 0.39129 & 0.42339 & 45 \\
\hline & 0.1 & 5.95844 & 0.99262 & 1.47615 & 0.27219 & 0.34957 & 0.37824 & 18 \\
\hline \multirow{3}{*}{0.01} & 0.05 & 5.16763 & 8.09678 & 1.76368 & 0.24326 & 0.36346 & 0.39328 & 175 \\
\hline & 0.1 & 4.80432 & 3.88106 & 1.51843 & 0.26743 & 0.35186 & 0.38072 & 72 \\
\hline & 0.15 & 4.58403 & 2.75661 & 1.37865 & 0.28400 & 0.34390 & 0.37211 & 47 \\
\hline
\end{tabular}

TABLE 4: Effects of incorrect preestimate " $\alpha$ " on optimal ALT plans $\left(A_{1}=1.5, A_{2}=3, \eta=5, \alpha=0.9, c=3.5\right.$, and $\left.k=4, \mathrm{~V}^{*}=1.30435\right)$.

\begin{tabular}{|c|c|c|c|c|c|c|}
\hline \multirow{2}{*}{$\%$ change } & \multicolumn{4}{|c|}{ Incorrect sample proportions } & \multirow{2}{*}{$\begin{array}{c}\text { Incorrect variance } \\
\qquad \mathrm{V}^{* *}\end{array}$} & \multirow{2}{*}{$\begin{array}{c}\text { \% deviation } \\
\text { PD }\end{array}$} \\
\hline & $\alpha$ & $\phi_{1}{ }^{*}$ & $\phi_{2}{ }^{*}$ & $\phi_{3}{ }^{*}$ & & \\
\hline $1 \%$ & 0.909 & 0.36852 & 0.50889 & 0.12260 & 1.29050 & 1.06182 \\
\hline$-1 \%$ & 0.918 & 0.25565 & 0.28443 & 0.45992 & 1.30919 & 0.37156 \\
\hline $2 \%$ & 0.927 & 0.37624 & 0.52376 & 0.10000 & 1.26266 & 3.19600 \\
\hline$-2 \%$ & 0.936 & 0.22676 & 0.25874 & 0.51449 & 1.31231 & 0.61030 \\
\hline $3 \%$ & 0.945 & 0.37750 & 0.52250 & 0.10000 & 1.23615 & 5.22824 \\
\hline$-3 \%$ & 0.891 & 0.20252 & 0.24549 & 0.55199 & 1.31570 & 0.87059 \\
\hline
\end{tabular}

TABLE 5: Effects of incorrect preestimate " $c$ " on optimal ALT plans $\left(A_{1}=1.5, A_{2}=3, \eta=5, \alpha=0.9, c=3.5\right.$, and $k=4$, $\left.\mathrm{V}^{*}=1.30435\right)$.

\begin{tabular}{|c|c|c|c|c|c|c|}
\hline \multirow{2}{*}{$\%$ change } & \multicolumn{4}{|c|}{ Incorrect sample proportions } & \multirow{2}{*}{$\begin{array}{c}\text { Incorrect variance } \\
\qquad \mathrm{V}^{* *}\end{array}$} & \multirow{2}{*}{$\begin{array}{c}\text { \% deviation } \\
\text { PD }\end{array}$} \\
\hline & $c$ & $\phi_{1}{ }^{*}$ & $\phi_{2}{ }^{*}$ & $\phi_{3}{ }^{*}$ & & \\
\hline $1 \%$ & 3.535 & 0.23483 & 0.26473 & 0.50044 & 1.28556 & 1.44015 \\
\hline$-1 \%$ & 3.570 & 0.37585 & 0.52415 & 0.10000 & 1.29585 & 0.65107 \\
\hline $2 \%$ & 3.605 & 0.19437 & 0.24250 & 0.56313 & 1.26608 & 2.93382 \\
\hline$-2 \%$ & 3.640 & 0.37800 & 0.52200 & 0.10000 & 1.27416 & 2.31434 \\
\hline $3 \%$ & 3.675 & 0.16283 & 0.23735 & 0.59982 & 1.25043 & 4.13323 \\
\hline$-3 \%$ & 3.465 & 0.37927 & 0.52073 & 0.10000 & 1.25527 & 3.76273 \\
\hline
\end{tabular}

\section{Conclusion}

In this paper we have formulated an optimum time-censored constant-stress PALTSP for the Burr type XII life distribution using hazard acceleration. Single sampling plan by variables has been used. The acceptance/rejection decision of the lot involves $k$-method in which Schneider's [9] approach has been used with sample mean replaced by MLE of location parameter and standard deviation replaced by MLE of scale parameter of the log-lifetime distribution with lower specification limit specified. The optimum plan consists in finding optimum allocation at normal operating condition and accelerated conditions by minimizing the variance of the test statistic meant for deciding on lot acceptability. The sensitivity analysis has been carried out and it has been found that if the misspecified values of the parameters are not too far from the true values, the optimum plan is robust. 


\section{Appendices}

A.

The elements of Fisher Information matrix are

$$
\begin{aligned}
& E\left[-\frac{\partial^{2} \ln L_{u_{i}}}{\partial A_{1}^{2}}\right]=0, \\
& E\left[-\frac{\partial^{2} \ln L_{u_{i}}}{\partial A_{1} A_{2}}\right]=0, \\
& E\left[-\frac{\partial^{2} \ln L_{u_{i}}}{\partial \alpha \partial A_{1}}\right]=0, \\
& E\left[-\frac{\partial^{2} \ln L_{u_{i}}}{\partial c \partial A_{1}}\right]=0, \\
& E\left[-\frac{\partial^{2} \ln L_{u_{i}}}{\partial A_{2}^{2}}\right]=0, \\
& E\left[-\frac{\partial^{2} \ln L_{u_{i}}}{\partial \alpha \partial A_{2}}\right]=0 \text {, } \\
& E\left[-\frac{\partial^{2} \ln L_{u_{i}}}{\partial c \partial A_{2}}\right]=0 \text {, } \\
& E\left[-\frac{\partial^{2} \ln L_{u_{i}}}{\partial \alpha^{2}}\right] \\
& =\left(\frac{c}{\alpha}\right)^{2} \cdot\{k(k+1) \\
& \times \int_{-\infty}^{\left(\eta^{\prime}-\mu\right) / \sigma}\left(\frac{e^{2\left(\left(t_{i}-\mu\right) / \sigma\right)}}{\sigma\left(1+e^{\left(t_{i}-\mu\right) / \sigma}\right)^{k+3}}\right) d t_{i} \\
& \left.+k\left(\frac{e^{\left(\eta^{\prime}-\mu\right) / \sigma}}{\left(1+e^{\left(\eta^{\prime}-\mu\right) / \sigma}\right)^{k+2}}\right)\right\}, \\
& E\left[-\frac{\partial^{2} \ln L_{u_{i}}}{\partial c \partial \alpha}\right] \\
& =\left(-\frac{1}{\alpha}\right) \cdot\{k(k+1) \\
& \times \int_{-\infty}^{\left(\eta^{\prime}-\mu\right) / \sigma}\left(\frac{\left(\left(t_{i}-\mu\right) / \sigma\right) e^{2\left(\left(t_{i}-\mu\right) / \sigma\right)}}{\sigma\left(1+e^{\left(t_{i}-\mu\right) / \sigma}\right)^{k+3}}\right) d t_{i} \\
& \left.+\frac{k\left(\left(\eta^{\prime}-\mu\right) / \sigma\right) e^{\left(\eta^{\prime}-\mu\right) / \sigma}}{\left(1+e^{\left(\eta^{\prime}-\mu\right) / \sigma}\right)^{k+2}}\right\},
\end{aligned}
$$

$$
E\left[-\frac{\partial^{2} \ln L_{u_{i}}}{\partial c^{2}}\right]
$$$$
=\left(\frac{1}{c^{2}}\right) \cdot\left\{\left(1-\left(1+e^{\left(\eta^{\prime}-\mu\right) / \sigma}\right)^{-k}\right)+k(k+1)\right.
$$$$
\times \int_{-\infty}^{\left(\eta^{\prime}-\mu\right) / \sigma}\left(\frac{\left(\left(t_{i}-\mu\right) / \sigma\right)^{2} e^{2\left(\left(t_{i}-\mu\right) / \sigma\right)}}{\sigma\left(1+e^{\left(t_{i}-\mu\right) / \sigma}\right)^{k+3}}\right) d t_{i}
$$$$
\left.+\frac{k\left(\left(\eta^{\prime}-\mu\right) / \sigma\right)^{2} e^{\left(\eta^{\prime}-\mu\right) / \sigma}}{\left(1+e^{\left(\eta^{\prime}-\mu\right) / \sigma}\right)^{k+2}}\right\}
$$$$
E\left[-\frac{\partial^{2} \ln L_{a_{1 j}}}{\partial A_{1}^{2}}\right]=\left(\frac{1}{A_{1}}\right)^{2} \cdot\left(1-\left(1+e^{\left(\eta^{\prime}-\mu\right) / \sigma}\right)^{-k A_{1}}\right),
$$$$
E\left[-\frac{\partial^{2} \ln L_{a_{1 j}}}{\partial \alpha \partial A_{1}}\right]
$$$$
=\left(-\frac{c}{\alpha}\right) \cdot\left\{k\left(k A_{1}\right)\right.
$$$$
\times \int_{-\infty}^{\left(\eta^{\prime}-\mu\right) / \sigma}\left(\frac{e^{2\left(\left(t_{1 j}-\mu\right) / \sigma\right)}}{\sigma\left(1+e^{\left(t_{1 j}-\mu\right) / \sigma}\right)^{k A_{1}+2}}\right) d t_{1 j}
$$$$
\left.+k\left(\frac{e^{\left(\eta^{\prime}-\mu\right) / \sigma}}{\left(1+e^{\left(\eta^{\prime}-\mu\right) / \sigma}\right)^{k A_{1}+1}}\right)\right\}
$$

$$
\begin{aligned}
& E\left[-\frac{\partial^{2} \ln L_{a_{1 j}}}{\partial c \partial A_{1}}\right] \\
& =\left(\frac{1}{c}\right) \cdot\left\{k\left(k A_{1}\right)\right.
\end{aligned}
$$

$$
\begin{gathered}
\times \int_{-\infty}^{\left(\eta^{\prime}-\mu\right) / \sigma}\left(\frac{\left(\left(t_{1 j}-\mu\right) / \sigma\right) e^{2\left(\left(t_{1 j}-\mu\right) / \sigma\right)}}{\sigma\left(1+e^{\left(t_{1 j}-\mu\right) / \sigma}\right)^{k A_{1}+2}}\right) d t_{1 j} \\
\left.+k\left(\frac{\left(\left(\eta^{\prime}-\mu\right) / \sigma\right) e^{\left(\eta^{\prime}-\mu\right) / \sigma}}{\left(1+e^{\left(\eta^{\prime}-\mu\right) / \sigma}\right)^{k A_{1}+1}}\right)\right\}, \\
E\left[-\frac{\partial^{2} \ln L_{a_{1 j}}}{\partial \alpha^{2}}\right]
\end{gathered}
$$


Journal of Quality and Reliability Engineering

11

$$
\begin{aligned}
& =\left(\frac{c}{\alpha}\right)^{2} \cdot\left\{k A_{1}\left(k A_{1}+1\right)\right. \\
& \times \int_{-\infty}^{\left(\eta^{\prime}-\mu\right) / \sigma}\left(\frac{\ln \left(1+e^{\left(t_{2 j}-\mu\right) / \sigma}\right) e^{\left(t_{2 j}-\mu\right) / \sigma}}{\sigma\left(1+e^{\left(t_{2 j}-\mu\right) / \sigma}\right)^{k A_{1} A_{2}+1}}\right) d t_{2 j} \\
& \times \int_{-\infty}^{\left(\eta^{\prime}-\mu\right) / \sigma}\left(\frac{e^{2\left(\left(t_{1 j}-\mu\right) / \sigma\right)}}{\sigma\left(1+e^{\left(t_{1 j}-\mu\right) / \sigma}\right)^{k A_{1}+3}}\right) d t_{1 j} \\
& \left.+k\left(\frac{\ln \left(1+e^{\left(\eta^{\prime}-\mu\right) / \sigma}\right) e^{\left(\eta^{\prime}-\mu\right) / \sigma}}{\left(1+e^{\left(\eta^{\prime}-\mu\right) / \sigma}\right)^{k A_{1} A_{2}}}\right)\right\}, \\
& \left.+k A_{1}\left(\frac{e^{\left(\eta^{\prime}-\mu\right) / \sigma}}{\left(1+e^{\left(\eta^{\prime}-\mu\right) / \sigma}\right)^{k A_{1}+2}}\right)\right\}, \\
& E\left[-\frac{\partial^{2} \ln L_{a_{2 j}}}{\partial \alpha \partial A_{1}}\right] \\
& E\left[-\frac{\partial^{2} \ln L_{a_{1 j}}}{\partial c \partial \alpha}\right] \\
& =\left(-\frac{c}{\alpha}\right) \cdot\left\{k A_{2}\left(k A_{1} A_{2}\right)\right. \\
& =\left(-\frac{1}{\alpha}\right) \cdot\left\{k A_{1}\left(k A_{1}+1\right)\right. \\
& \times \int_{-\infty}^{\left(\eta^{\prime}-\mu\right) / \sigma}\left(\frac{e^{2\left(\left(t_{2 j}-\mu\right) / \sigma\right)}}{\sigma\left(1+e^{\left(t_{2 j}-\mu\right) / \sigma}\right)^{k A_{1} A_{2}+2}}\right) d t_{2 j} \\
& \times \int_{-\infty}^{\left(\eta^{\prime}-\mu\right) / \sigma}\left(\frac{\left(\left(t_{1 j}-\mu\right) / \sigma\right) e^{2\left(\left(t_{1 j}-\mu\right) / \sigma\right)}}{\sigma\left(1+e^{\left(t_{1 j}-\mu\right) / \sigma}\right)^{k A_{1}+3}}\right) d t_{1 j} \\
& \left.+k A_{2}\left(\frac{e^{\left(\eta^{\prime}-\mu\right) / \sigma}}{\left(1+e^{\left(\eta^{\prime}-\mu\right) / \sigma}\right)^{k A_{1} A_{2}+1}}\right)\right\}, \\
& \left.+k A_{1} \frac{\left(\left(\eta^{\prime}-\mu\right) / \sigma\right) e^{\left(\eta^{\prime}-\mu\right) / \sigma}}{\left(1+e^{\left(\eta^{\prime}-\mu\right) / \sigma}\right)^{k A_{1}+2}}\right\}, \\
& E\left[-\frac{\partial^{2} \ln L_{a_{1 j}}}{\partial c^{2}}\right] \\
& =\left(\frac{1}{c^{2}}\right) \cdot\left\{k A_{1}\left(k A_{1}+1\right)\right. \\
& \times \int_{-\infty}^{\left(\eta^{\prime}-\mu\right) / \sigma}\left(\frac{\left(\left(t_{2 j}-\mu\right) / \sigma\right) e^{2\left(\left(t_{2 j}-\mu\right) / \sigma\right)}}{\sigma\left(1+e^{\left(t_{2 j}-\mu\right) / \sigma}\right)^{k A_{1} A_{2}+2}}\right) d t_{2 j} \\
& \left.+k A_{2}\left(\frac{\left(\left(\eta^{\prime}-\mu\right) / \sigma\right) e^{\left(\eta^{\prime}-\mu\right) / \sigma}}{\left(1+e^{\left(\eta^{\prime}-\mu\right) / \sigma}\right)^{k A_{1} A_{2}+1}}\right)\right\}, \\
& \times \int_{-\infty}^{\left(\eta^{\prime}-\mu\right) / \sigma}\left(\frac{\left(\left(t_{1 j}-\mu\right) / \sigma\right)^{2} e^{2\left(\left(t_{1 j}-\mu\right) / \sigma\right)}}{\sigma\left(1+e^{\left(t_{1 j}-\mu\right) / \sigma}\right)^{k A_{1}+3}}\right) d t_{1 j} \\
& +\left(1-\left(1+e^{\left(\eta^{\prime}-\mu\right) / \sigma}\right)^{-k A_{1}}\right) \\
& \left.+k A_{1} \frac{\left(\left(\eta^{\prime}-\mu\right) / \sigma\right)^{2} e^{\left(\eta^{\prime}-\mu\right) / \sigma}}{\left(1+e^{\left(\eta^{\prime}-\mu\right) / \sigma}\right)^{k A_{1}+2}}\right\} \text {. } \\
& E\left[-\frac{\partial^{2} \ln L_{a_{2 j}}}{\partial c \partial A_{1}}\right] \\
& =\left(\frac{1}{c}\right) \cdot\left\{k A_{2}\left(k A_{1} A_{2}\right)\right. \\
& E\left[-\frac{\partial^{2} \ln L_{a_{2 j}}}{\partial A_{2}^{2}}\right]=\left(\frac{1}{A_{2}}\right)^{2} \cdot\left(1-\left(1+e^{\left(\eta^{\prime}-\mu\right) / \sigma}\right)^{-k A_{1} A_{2}}\right) \text {, } \\
& E\left[-\frac{\partial^{2} \ln L_{a_{2 j}}}{\partial \alpha \partial A_{2}}\right] \\
& =\left(-\frac{c}{\alpha}\right) \cdot\left\{k A_{1}\left(k A_{1} A_{2}\right)\right. \\
& E\left[-\frac{\partial^{2} \ln L_{a_{2 j}}}{\partial A_{1}^{2}}\right]=\left(\frac{1}{A_{1}}\right)^{2} \cdot\left(1-\left(1+e^{\left(\eta^{\prime}-\mu\right) / \sigma}\right)^{-k A_{1} A_{2}}\right), \\
& E\left[-\frac{\partial^{2} \ln L_{a_{2 j}}}{\partial A_{2} \partial A_{1}}\right] \\
& \times \int_{-\infty}^{\left(\eta^{\prime}-\mu\right) / \sigma}\left(\frac{e^{2\left(\left(t_{2 j}-\mu\right) / \sigma\right)}}{\sigma\left(1+e^{\left(t_{2 j}-\mu\right) / \sigma}\right)^{k A_{1} A_{2}+2}}\right) d t_{2 j} \\
& =\left(\frac{1}{c}\right) \\
& \left.+k A_{1}\left(\frac{e^{\left(\eta^{\prime}-\mu\right) / \sigma}}{\left(1+e^{\left(\eta^{\prime}-\mu\right) / \sigma}\right)^{k A_{1} A_{2}+1}}\right)\right\} \text {, } \\
& \left\{k\left(k A_{1} A_{2}\right)\right. \\
& E\left[-\frac{\partial^{2} \ln L_{a_{2 j}}}{\partial c \partial A_{2}}\right]
\end{aligned}
$$




$$
\begin{aligned}
=\left(\frac{1}{c}\right) \cdot\{ & k A_{1}\left(k A_{1} A_{2}\right) \\
& \times \int_{-\infty}^{\left(\eta^{\prime}-\mu\right) / \sigma}\left(\frac{\left(\left(t_{2 j}-\mu\right) / \sigma\right) e^{2\left(\left(t_{2 j}-\mu\right) / \sigma\right)}}{\sigma\left(1+e^{\left(t_{2 j}-\mu\right) / \sigma}\right)^{k A_{1} A_{2}+2}}\right) d t_{2 j} \\
& \left.+k A_{1}\left(\frac{\left(\left(\eta^{\prime}-\mu\right) / \sigma\right) e^{\left(\eta^{\prime}-\mu\right) / \sigma}}{\left(1+e^{\left(\eta^{\prime}-\mu\right) / \sigma}\right)^{k A_{1} A_{2}+1}}\right)\right\}
\end{aligned}
$$$$
E\left[-\frac{\partial^{2} \ln L_{a_{2 j}}}{\partial \alpha^{2}}\right]
$$$$
=\left(\frac{c}{\alpha}\right)^{2} \cdot\left\{k A_{1} A_{2}\left(k A_{1} A_{2}+1\right)\right.
$$$$
\times \int_{-\infty}^{\left(\eta^{\prime}-\mu\right) / \sigma}\left(\frac{e^{2\left(\left(t_{2 j}-\mu\right) / \sigma\right)}}{\sigma\left(1+e^{\left(t_{2 j}-\mu\right) / \sigma}\right)^{k A_{1} A_{2}+3}}\right) d t_{2 j}
$$$$
\left.+k A_{1} A_{2}\left(\frac{e^{\left(\eta^{\prime}-\mu\right) / \sigma}}{\left(1+e^{\left(\eta^{\prime}-\mu\right) / \sigma}\right)^{k A_{1} A_{2}+2}}\right)\right\},
$$$$
E\left[-\frac{\partial^{2} \ln L_{a_{2 j}}}{\partial c \partial \alpha}\right]
$$$$
=\left(-\frac{1}{\alpha}\right) \cdot\left\{k A_{1} A_{2}\left(k A_{1} A_{2}+1\right)\right.
$$$$
\times \int_{-\infty}^{\left(\eta^{\prime}-\mu\right) / \sigma}\left(\frac{\left(\left(t_{2 j}-\mu\right) / \sigma\right) e^{2\left(\left(t_{2 j}-\mu\right) / \sigma\right)}}{\sigma\left(1+e^{\left(t_{2 j}-\mu\right) / \sigma}\right)^{k A_{1} A_{2}+3}}\right) d t_{2 j}
$$$$
\left.+\frac{k A_{1} A_{2}\left(\left(\eta^{\prime}-\mu\right) / \sigma\right) e^{\left(\eta^{\prime}-\mu\right) / \sigma}}{\left(1+e^{\left(\eta^{\prime}-\mu\right) / \sigma}\right)^{k A_{1} A_{2}+2}}\right\}
$$$$
E\left[-\frac{\partial^{2} \ln L_{a_{2 j}}}{\partial c^{2}}\right]
$$$$
=\left(\frac{1}{c^{2}}\right) \cdot\left\{k A_{1} A_{2}\left(k A_{1} A_{2}+1\right)\right.
$$$$
\times \int_{-\infty}^{\left(\eta^{\prime}-\mu\right) / \sigma}\left(\frac{\left(\left(t_{2 j}-\mu\right) / \sigma\right)^{2} e^{2\left(\left(t_{2 j}-\mu\right) / \sigma\right)}}{\sigma\left(1+e^{\left(t_{2 j}-\mu\right) / \sigma}\right)^{k A_{1} A_{2}+3}}\right) d t_{2 j}
$$

$$
\begin{aligned}
& +\left(1-\left(1+e^{\left(\eta^{\prime}-\mu\right) / \sigma}\right)^{-k A_{1} A_{2}}\right) \\
& \left.+\frac{k A_{1} A_{2}\left(\left(\eta^{\prime}-\mu\right) / \sigma\right)^{2} e^{\left(\eta^{\prime}-\mu\right) / \sigma}}{\left(1+e^{\left(\eta^{\prime}-\mu\right) / \sigma}\right)^{k A_{1} A_{2}+2}}\right\} .
\end{aligned}
$$

B.

Using delta method, $V$ in (20) has been obtained. Let

$$
\begin{aligned}
\frac{V_{1}}{n} & =\operatorname{Asvar}\left(\widehat{\mu}_{0}\right)=\operatorname{Asvar}(\ln (\alpha)) \\
& =\operatorname{Asvar}\left[\widehat{h}_{1}\left(\widehat{A}_{1}, \widehat{A}_{2}, \widehat{\alpha}, \widehat{c}\right)\right]=\widehat{H}_{1}^{\prime} F^{-1} \widehat{H}_{1},
\end{aligned}
$$

where $\widehat{H}_{1}^{\prime}$ is a transpose of ${\widehat{H_{1}}}_{1}$ and

$$
\underline{\widehat{H}_{1}}=\left[\begin{array}{llll}
\frac{\partial \widehat{h}_{1}}{\partial \widehat{A}_{1}} & \frac{\partial \widehat{h}_{1}}{\partial \widehat{A}_{2}} & \frac{\partial \widehat{h}_{1}}{\partial \widehat{\alpha}} & \frac{\partial \widehat{h}_{1}}{\partial \widehat{c}}
\end{array}\right]^{\prime} .
$$

Further, let

$$
\begin{aligned}
\frac{V_{2}}{n} & =\operatorname{Ascov}\left(\widehat{\mu}_{0}, \widehat{\sigma}_{0}\right)=\operatorname{Ascov}\left(\ln (\alpha),(c)^{-1}\right) \\
& =\operatorname{Ascov}\left[\widehat{h}_{1}\left(\widehat{A}_{1}, \widehat{A}_{2}, \widehat{\alpha}, \widehat{c}\right), \widehat{h}_{2}\left(\widehat{A}_{1}, \widehat{A}_{2}, \widehat{\alpha}, \widehat{c}\right)\right], \\
\frac{V_{3}}{n} & =\operatorname{Asvar}\left(\widehat{\sigma}_{0}\right)=\operatorname{Asvar}\left((c)^{-1}\right) \\
& =\operatorname{Asvar}\left[\widehat{h}_{2}\left(\widehat{A}_{1}, \widehat{A}_{2}, \widehat{\alpha}, \widehat{c}\right)\right]=\underline{\hat{H}_{2}^{\prime}} F^{-1} \widehat{H}_{2},
\end{aligned}
$$

where $\widehat{H}_{2}^{\prime}$ is a transpose of ${\widehat{H_{2}}}_{2}$ and

$$
\underline{\widehat{H}_{2}}=\left[\begin{array}{llll}
\frac{\partial \widehat{h}_{2}}{\partial \widehat{A}_{1}} & \frac{\partial \widehat{h}_{2}}{\partial \widehat{A}_{2}} & \frac{\partial \widehat{h}_{2}}{\partial \widehat{\alpha}} & \frac{\partial \widehat{h}_{2}}{\partial \widehat{c}}
\end{array}\right]^{\prime} .
$$

Then,

$$
\operatorname{Asvar}\left(T^{\prime}\right)=\frac{\left(V_{1}-2 k V_{2}+k^{2} V_{3}\right)}{n}=\frac{V}{n} .
$$

\section{Acronyms}

\section{ALT: $\quad$ Accelerated life test}

ALTSP: Accelerated life test sampling plan

PALT: Partially accelerated life test

PALTSP: Partially accelerated life test sampling plan

Asvar: Asymptotic variance

Ascov: Asymptotic covariance

cdf: Cumulative distribution function

pdf: Probability density function

MLE: Maximum likelihood estimate. 


\begin{tabular}{|c|c|}
\hline$A_{1}, A_{2}:$ & Acceleration factors $\left(A_{2}>A_{1}>1\right)$ \\
\hline$A_{i}^{*}:$ & $\prod_{k=1}^{i} A_{k}, i=1,2$ \\
\hline$\phi_{1}, \phi_{2}, \phi_{3}:$ & $\begin{array}{l}\text { Proportion of sample allocated to } \\
\text { normal operating condition, accel- } \\
\text { erated condition } A_{1}^{*} \text {, and accel- } \\
\text { erated condition } A_{2}^{*} \text {, respectively, } \\
\text { where } \sum_{i=1}^{3} \phi_{i}=1\end{array}$ \\
\hline$\phi_{i}^{*}:$ & $\begin{array}{l}\text { Optimum proportion of sample } \\
\text { allocated to normal operating } \\
\text { condition, accelerated condition } \\
A_{1} \text {, and accelerated condition } A_{2} \text {, } \\
\text { respectively, where } \sum_{i=1}^{3} \phi_{i}^{*}=1\end{array}$ \\
\hline$n:$ & $\begin{array}{l}\text { Total number of test items in a } \\
\text { PALTSP }\end{array}$ \\
\hline$n \phi_{i}:$ & $\begin{array}{l}\text { Items allocated to normal operat- } \\
\text { ing condition, accelerated condi- } \\
\text { tion } A_{1} \text {, and accelerated condition } \\
A_{2} \text {, respectively, } i=1,2,3\end{array}$ \\
\hline$n_{u}, n_{a_{1}}, n_{a_{2}}:$ & $\begin{array}{l}\text { Number of items failed at nor- } \\
\text { mal operating condition, acceler- } \\
\text { ated condition } A_{1} \text {, and accelerated } \\
\text { condition } A_{2}^{*} \text {, respectively }\end{array}$ \\
\hline$n_{u_{c}}, n_{a_{1 c}}, n_{a_{2 c}}:$ & $\begin{array}{l}\text { Number of censored items at nor- } \\
\text { mal operating condition, acceler- } \\
\text { ated condition } A_{1} \text {, and accelerated } \\
\text { condition } A_{2} \text {, respectively }\end{array}$ \\
\hline$Y, X_{1} \& X_{2}$ & $\begin{array}{l}\text { Lifetime of an item at normal oper- } \\
\text { ating condition, accelerated condi- } \\
\text { tion } A_{1} \text {, and accelerated condition } \\
A_{2} \text {, respectively }\end{array}$ \\
\hline$T:$ & $\ln Y$ \\
\hline$t_{i}:$ & $\begin{array}{l}\text { Observed log-lifetime of } i \text { th item } \\
\text { tested at normal operating condi- } \\
\text { tion }\end{array}$ \\
\hline$t_{1 j}:$ & $\begin{array}{l}\text { Observed log-lifetime of } j \text { th item } \\
\text { tested at accelerated condition } A_{1}\end{array}$ \\
\hline$t_{2 j}:$ & $\begin{array}{l}\text { Observed log-lifetime of } j \text { th item } \\
\text { tested at accelerated condition } A_{2}\end{array}$ \\
\hline$\eta:$ & Censoring time \\
\hline$\eta^{\prime}:$ & Log-censoring time \\
\hline$\alpha:$ & Scale parameter $(\alpha>0)$ \\
\hline$c, k:$ & Shape parameter $(c>0, k>0)$ \\
\hline$F(\cdot):$ & Cumulative distribution function \\
\hline$f_{1}(\cdot):$ & $\begin{array}{l}\text { Probability density function at nor- } \\
\text { mal operating condition }\end{array}$ \\
\hline$R_{1}(\cdot):$ & $\begin{array}{l}\text { Reliability function at normal oper- } \\
\text { ating condition }\end{array}$ \\
\hline$h_{1}(\cdot):$ & $\begin{array}{l}\text { Hazard (failure) rate at normal } \\
\text { operating condition }\end{array}$ \\
\hline$f_{i}(\cdot):$ & $\begin{array}{l}\text { Probability density function at } \\
\text { accelerated conditions } A_{i}, i=1,2\end{array}$ \\
\hline$R_{i}(\cdot):$ & $\begin{array}{l}\text { Reliability function at accelerated } \\
\text { conditions } A_{i}, i=1,2\end{array}$ \\
\hline$h_{i}(\cdot):$ & $\begin{array}{l}\text { Hazard (failure) rate at accelerated } \\
\text { conditions } A_{i}, i=1,2\end{array}$ \\
\hline$\wedge:$ & A maximum likelihood estimate \\
\hline
\end{tabular}

$$
\begin{aligned}
& \delta_{u_{i}}, \delta_{a_{1}}, \delta_{a_{2 j}}: \quad \text { Indicator functions: } \\
& \delta_{u_{i}}=\left\{1, T_{i} \leq \eta^{\prime}, \quad i=\right. \\
& \left.1,2, \ldots, n_{u}, 0 \text {, otherwise }\right\} \text {; } \\
& \delta_{a_{1 j}}=\left\{1, T_{1 j} \leq \eta^{\prime}, \quad j=\right. \\
& \left.1,2, \ldots, n_{a_{1}}, 0 \text {, otherwise }\right\} \\
& \text { and } \delta_{a_{2 j}}=\left\{1, T_{2 j} \leq \eta^{\prime}, \quad j=\right. \\
& \left.1,2, \ldots, n_{a}, 0 \text {, otherwise }\right\} \text {. } \\
& t_{(1)}<t_{(2)}<\cdots<\text { Ordered log-lifetimes times at } \\
& t_{\left(n_{u}\right)}<\eta^{\prime}: \quad \text { normal operating condition } \\
& t_{(11)}<t_{(12)}<\cdots<\text { Ordered log-lifetimes at } \\
& t_{\left(1 n_{a_{1}}\right)}<\eta^{\prime}: \quad \text { accelerated condition } A_{1} \\
& t_{(21)}<t_{(22)}<\cdots<\text { Ordered log-lifetimes at } \\
& t_{\left(2 n_{a_{2}}\right)}<\eta^{\prime}: \quad \text { accelerated condition } A_{2} \text {. }
\end{aligned}
$$

\section{Conflict of Interests}

The authors declare that there is no conflict of interests regarding the publication of this paper.

\section{Acknowledgments}

The authors are grateful to the referees for their valuable comments. This research work is supported by R\&D Grant received from the University of Delhi, Delhi, India.

\section{References}

[1] W. Nelson, Accelerated Testing-Statistical Models, Test Plans, and Data Analyses, John Wiley \& Sons, New York, NY, USA, 1990.

[2] G.-B. Yang, "Optimum constant-stress accelerated life-test plans," IEEE Transactions on Reliability, vol. 43, no. 4, pp. 575581, 1994.

[3] M. H. DeGroot and P. K. Goel, "Bayesian estimation and optimal designs in partially accelerated life testing," Naval Research Logistics Quarterly, vol. 26, pp. 223-2235, 1979.

[4] D. S. Bai, S. W. Chung, and Y. R. Chun, "Optimal design of partially accelerated life tests for the lognormal distribution under type I censoring," Reliability Engineering and System Safety, vol. 40, no. 1, pp. 85-92, 1993.

[5] A. Ismail, The test design and parameter estimation of pareto lifetime distribution under partially accelerated life tests [Ph.D. thesis], Department of Statistics, Faculty of Economics \& Political Science, Cairo University, Cairo, Egypt, 2004.

[6] G. K. Bhattacharyya and Z. Soejoeti, "A tampered failure rate model for step-stress accelerated life test," Communication in Statistics-Theory and Methods, vol. 18, pp. 1627-11643, 1989.

[7] D. S. Bai and S. W. Chung, "Optimal design of partially accelerated life tests for the exponential distribution under typeI censoring," IEEE Transactions on Reliability, vol. 41, no. 3, pp. 400-406, 1992.

[8] A. H. Abdel-Hamid, "Constant-partially accelerated life tests for Burr type-XII distribution with progressive type-II censoring," Computational Statistics \& Data Analysis, vol. 53, no. 7, pp. 25112523, 2009.

[9] H. Schneider, "Failure-censored variables-sampling plans for lognormal and Weibull distributions," Technometrics, vol. 31, no. 2, pp. 199-206, 1989. 

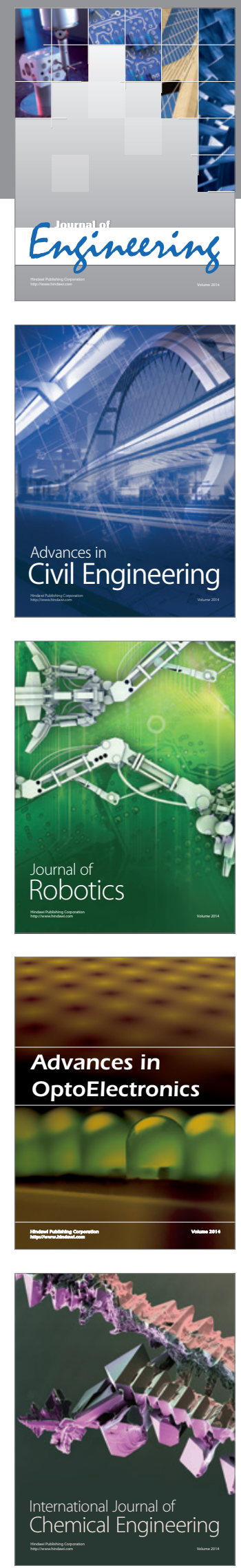

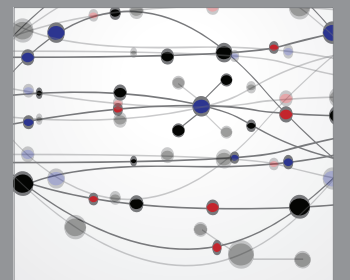

The Scientific World Journal
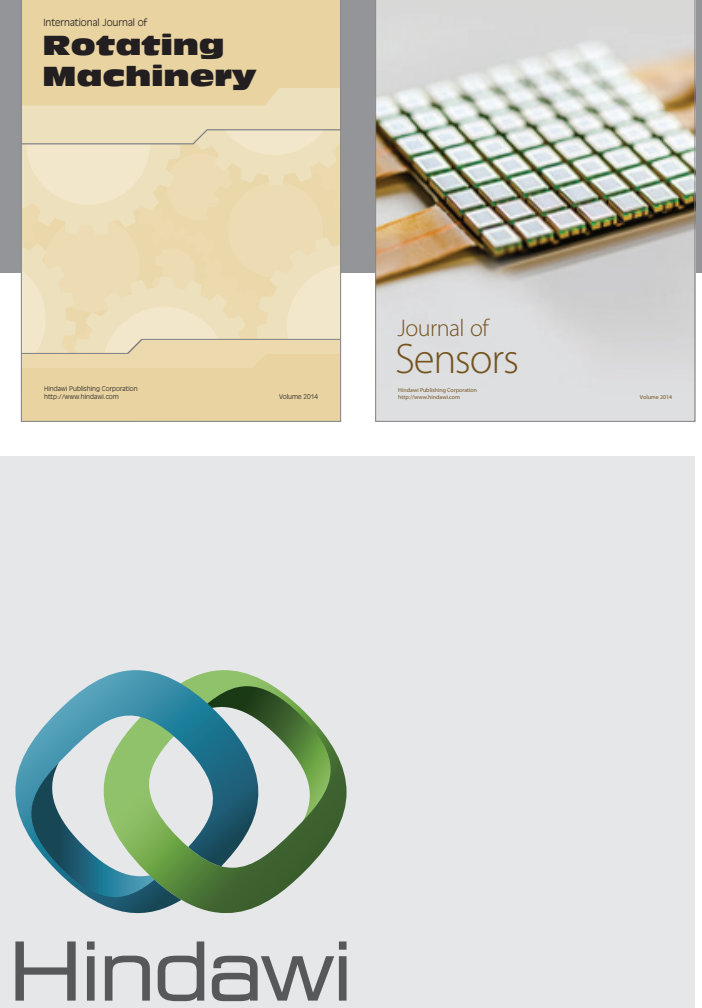

Submit your manuscripts at http://www.hindawi.com
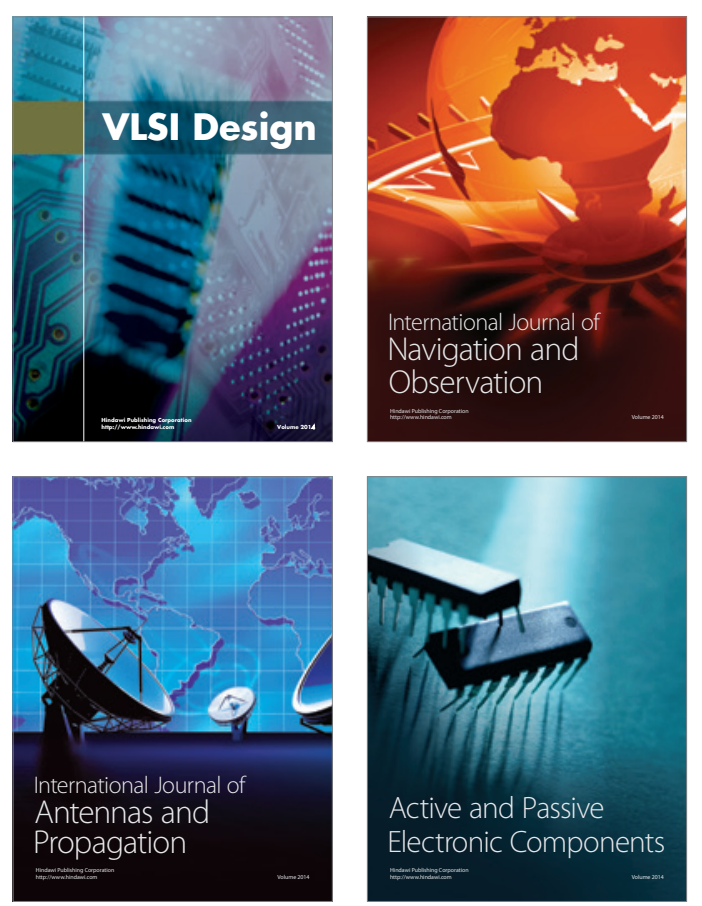
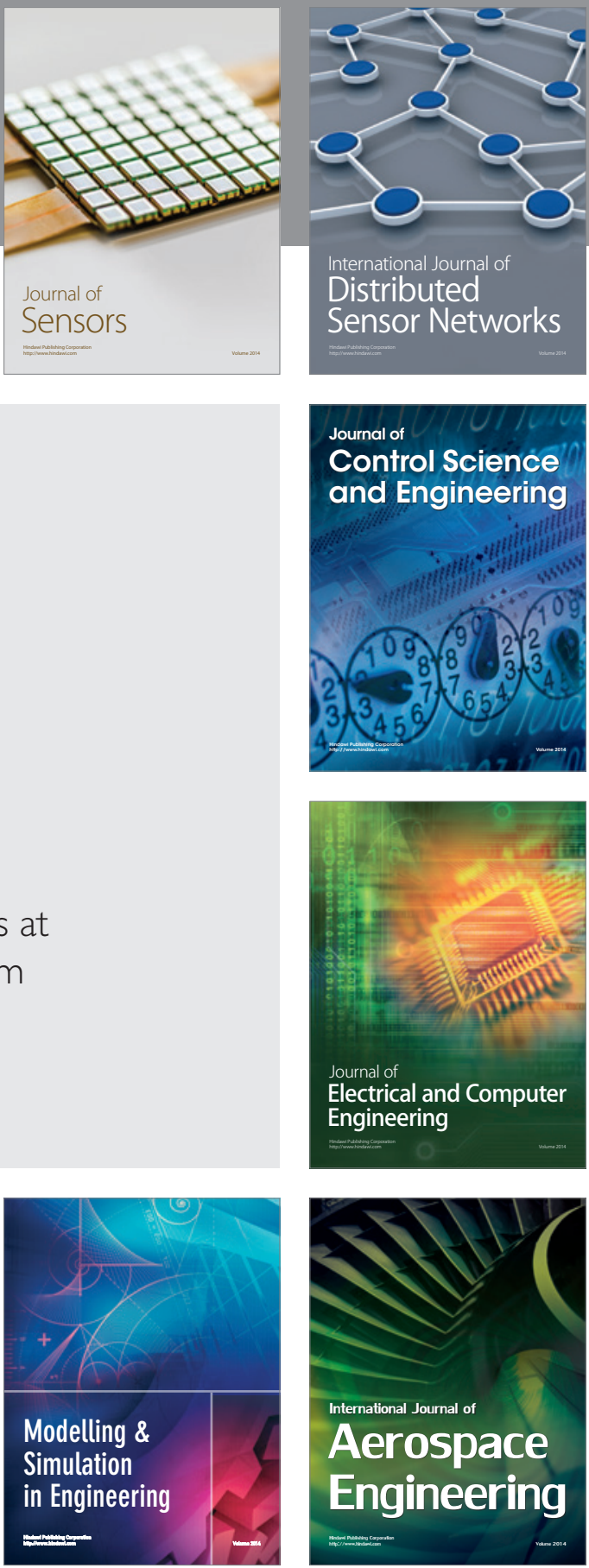

Journal of

Control Science

and Engineering
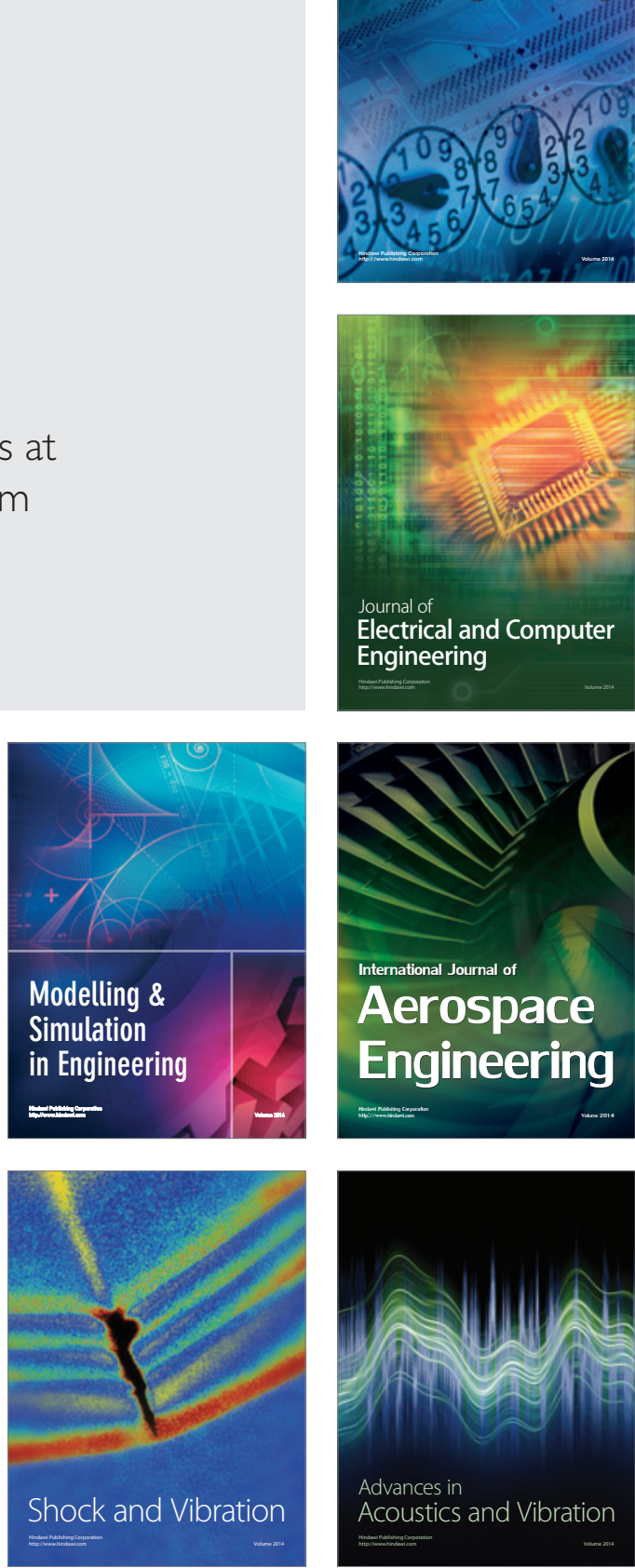